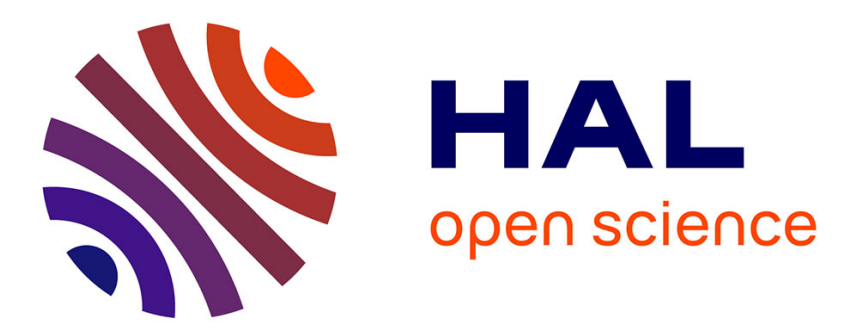

\title{
Degradation-by-design: how chemical functionalization enhances the biodegradability and safety of $2 \mathrm{D}$ materials
}

Baojin Ma, Cristina Martín, Rajendra Kurapati, Alberto Bianco

\section{To cite this version:}

Baojin Ma, Cristina Martín, Rajendra Kurapati, Alberto Bianco. Degradation-by-design: how chemical functionalization enhances the biodegradability and safety of $2 \mathrm{D}$ materials. Chemical Society Reviews, 2020, 49 (17), pp.6224-6247. 10.1039/c9cs00822e . hal-03001592

\section{HAL Id: hal-03001592 https://hal.science/hal-03001592}

Submitted on 16 Nov 2020

HAL is a multi-disciplinary open access archive for the deposit and dissemination of scientific research documents, whether they are published or not. The documents may come from teaching and research institutions in France or abroad, or from public or private research centers.
L'archive ouverte pluridisciplinaire HAL, est destinée au dépôt et à la diffusion de documents scientifiques de niveau recherche, publiés ou non, émanant des établissements d'enseignement et de recherche français ou étrangers, des laboratoires publics ou privés. 


\title{
Degradation-by-design: how chemical functionalization enhances the biodegradability and safety of 2D materials
}

\author{
Baojin Ma, ${ }^{1}$ Cristina Martín, ${ }^{1}$ Rajendra Kurapati, ${ }^{2}$ Alberto Bianco ${ }^{1, *}$ \\ ${ }^{1}$ CNRS, Immunology, immunopathology and therapeutic chemistry, UPR 3572, University of \\ Strasbourg, ISIS, 67000 Strasbourg, France \\ 2 ÚRAM, SFI Research Centre for Medical Devices, National University of Ireland, Galway H91 \\ W2TY, Ireland
}

Corresponding authors: Alberto Bianco, a.bianco@ibmc-cnrs.unistra.fr

Keywords: Carbon nanomaterials, graphene, toxicity, therapy, imaging 


\section{Abstract}

A large number of graphene and other 2D materials are currently used for the development of new technologies, increasingly entering different industrial sectors. Interrogating the impact of such 2D materials on health and environment is crucial for both modulating their potential toxicity in living organisms and eliminating them from the environment. In this context, understanding if 2D materials are bio-persistent is mandatory. In this review we describe the importance of biodegradability and decomposition of $2 \mathrm{D}$ materials. We initially cover the biodegradation of graphene family materials, followed by other emerging classes of $2 \mathrm{D}$ materials including transition metal dichalcogenides and oxides, Xenes, Mxenes and other non-metallic 2D materials. We explain the role of defects and functional groups, introduced onto the surface of the materials during their preparation, and the consequences of chemical functionalization on biodegradability. In strong relation to the chemistry on 2D materials, we describe the concept of "degradation-by-design" that we contributed to develop, and which concerns the covalent modification with appropriate molecules to enhance the biodegradability of 2D materials. Finally, we cover the importance of designing new biodegradable 2D conjugates and devices for biomedical applications as drug delivery carriers, in bioelectronics, and tissue engineering. We would like to highlight that the biodegradation of $2 \mathrm{D}$ materials mainly depends on the type of material, the chemical functionalization, the aqueous dispersibility and the redox potentials of the different oxidative environments. Biodegradation is one of the necessary conditions for the safe application of 2D materials. Therefore, we hope that this review will help to better understand their biodegradation processes, and will stimulate the chemists to explore new chemical strategies to design safer products, composites and devices containing 2D materials. 


\section{Introduction}

2D layered materials consist of sheets of different atomic elements that can stack on top of each other, stabilized by van der Waals forces. ${ }^{1}$ If these layers are exfoliated into monolayers or fewlayers, new physicochemical properties show up. Graphene became the most popular 2D material since more than one decade. ${ }^{2}$ This material is a single atomic plane of graphite, made of $\mathrm{sp}^{2}-$ hybridized carbon atoms. Graphene monolayer has unprecedented properties, including roomtemperature quantum Hall effect, high carrier mobility, high thermal conductivity and a relatively high Young's modulus. ${ }^{3}$ However, graphene is not immune from structural defects. In fact, engineering defects on graphene has been a key approach to understand and tune its properties. In this context, a family of graphene materials has emerged in the last years, and these carbonbased materials can be classified depending on the carbon to oxygen ratio $(\mathrm{C} / \mathrm{O})$, the lateral size and the number of layers. ${ }^{4}$ These three properties can be mainly modulated by the production and processing methods. ${ }^{5}$ Graphene family materials (GFMs) like graphene oxide (GO), ${ }^{6}$ few-layer graphene (FLG) $)^{7,8}$ or graphene nanoribbons (GNRs), ${ }^{9}$ among others, have arisen as novel nanomaterials for different applications depending on their final properties. ${ }^{10,11}$ Regarding the industrial applications, GFMs have been already applied as conducting additives in electrodes for batteries, ${ }^{12}$ as additives in anti-corrosion primers, ${ }^{13}$ or as precursors for touch panels. ${ }^{14,15}$ In the biomedical field, GFMs have also gained a central role and they have been explored as effective platforms for drug delivery, ${ }^{16-18}$ as components of bioanalytical devices, ${ }^{19,20}$ or embedded into scaffolds for neuronal growth, ${ }^{21}$ and tissue engineering. ${ }^{22,23}$ In addition, functionalized graphene nanocomposites have demonstrated to ameliorate the photothermal properties for tumour treatment. ${ }^{24}$

The success of graphene and GFMs has been the inspiration of an equally remarkable development of other inorganic 2D materials consisting of single atomic sheets of different classes of compounds. ${ }^{25,26}$ These new materials include transition metal dichalcogenides (TMDs), hexagonal boron nitride ( $\mathrm{hBN}$, also known as white graphene), MXenes (2D carbides or nitrides), transition metal oxides (TMOs), 2D Xenes such as borophene, silicene, germanene, or phosphorene (also called black phosphorus, BP), and other 2D materials like layered double hydroxides (LDHs), ${ }^{27}$ metal-organic frameworks (MOFs), ${ }^{28,29}$ and covalent organic frameworks $(\mathrm{COFs})^{30}$ (Fig. 1).

We could consider TMDs as the first descendants of graphene, ${ }^{26,31}$ due to the properties similar to graphene and GFMs, like excellent electrical transport, high in-plane stiffness, Young's modulus, transparency and flexibility. ${ }^{32}$ 2D TMDs have a three-layer atomic structure, where the outside layers is made of chalcogens covalently bound to a metallic atom inner layer. Each of these layers is arranged in a triangular lattice. Some examples of TMDs are $\mathrm{MoS}_{2}, \mathrm{MoSe}_{2}, \mathrm{WS}_{2}, \mathrm{WSe}_{2}$, etc. This kind of 2D materials shows also unique electrical and optical properties due to a tuneable bandgap when bulk materials are processed as monolayers, which make them suitable candidates for a wide range of optoelectronic devices. ${ }^{33} \mathrm{MoS}_{2}$ is probably the most widely studied TMD until now, and it has been used as a solid industrial lubricant ${ }^{34}$ or as a catalyst, ${ }^{35}$ for instance. On the 
other hand, the bioapplications of TMDs are still at their infancy, ${ }^{36,37}$ despite some studies were reported mainly focusing on the development of electrochemical sensing of multifunctional targets. $\mathrm{MoS}_{2}$ nanostructures have been used to create sensors, which have demonstrated their prominent role in biological, environmental, and food analyses. ${ }^{38}$ Besides, their toxicity has been demonstrated to be low for $\mathrm{MoS}_{2}, \mathrm{WS}_{2}$ and $\mathrm{WSe}_{2 .}{ }^{39}$ Overall, TMDs reached the same potential of graphene after the discovery of their direct band gap, their high charge density and their valleytronics properties.

$\mathrm{hBN}$ is also among the most promising $2 \mathrm{D}$ layered nanomaterials. ${ }^{40} \mathrm{hBN}$ is composed of covalently bound alternating nitrogen and boron atoms. The high mechanical stiffness, wide band gap, and excellent thermal conductivity and stability, are at the origin of its applications. ${ }^{41}$ As it happens with TMDs or graphene, hBN hosts defects that were engineered to obtain for example room temperature single-photon emission. Besides, van der Waals heterostructures combining graphene and $\mathrm{hBN}$ have been recently reported. ${ }^{42} \mathrm{hBN}$ can tune the optical and electronic properties of graphene in new ways under specific conditions in order to induce secondary Dirac points or new plasmonic states. The integration of other van der Waals materials into these heterostructures can modify the degrees of freedom (e.g., interlayer spacing), which paves the way for the manipulation of the properties of limitless new devices. All features and possibilities offered by hBN have led to its use as field effect transistor, in tunnelling devices or in deep UV emitters. ${ }^{43}$ Exfoliated hBN films have been applied as well as coatings that withstand extreme environmental conditions. ${ }^{44}$ Future photonics functionalities are also expected for hBN, but there are still some obstacles such as limited synthesis and processing techniques. ${ }^{45} \mathrm{hBN}$ related structures seem to have a better biocompatibility and lower cytotoxicity than their carbon-based cousins, although more results are required. ${ }^{46}$ Despite one of the difficulties is the obtaining of good water dispersibility, some progressions indicate that the challenges related to BN material poor water dispersibility can be effectively addressed via chemical functionalization. ${ }^{47,48}$ The surface modification of hBN by covalent and non-covalent approaches has been extensively explored, to also prevent aggregation. ${ }^{40}$ Another important challenge is the biocompatibility of the material depending again on its physicochemical properties, purity or concentration. ${ }^{49}$ However, some research has been done in this field. ${ }^{43}$ Golberg and co-workers developed, for instance, a biocompatible hydroxyl hBN that could load $~ 300$ wt\% of doxorubicin (DOX), and exhibit much higher potency in reducing the viability of human prostate adenocarcinoma than the free drug. ${ }^{50}$

Silicene, the silicon equivalent of graphene,${ }^{51}$ and other periodic table group IV materials such as germanene or stanene, ${ }^{52,53}$ and group $V$ phosphorene (e.g., the single- or few-layer form of black phosphorus $)^{54}$ are considered as emerging 2D materials, grouped in the so-called family of Xenes. ${ }^{55-57}$ Compared to graphene, the bandgap value in silicene is not suitable for electronic devices, although it is emerging a new field of research interested in the phenomena of quantum spin Hall effect, which is one of the recent scientific attraction due to its importance for technological applications in the fields of 2D spintronics nanotechnology. Considering the quantum spin Hall effect, it is important to highlight that silicene is one step ahead compared to graphene due to its 
compatibility with the present matured silicon-based semiconductor technology. Regarding phosphorene, novel physical, chemical, and mechanical properties have led to the fabrication of phosphorus-based devices with promising potentials for applications in electronics, optoelectronics, photovoltaics, and spintronics. ${ }^{58,59}$ Besides, phosphorene offers a desirable characteristic for radio-frequency applications that is lacking in graphene-based field effect transistors. ${ }^{60}$ Due to stability issues, the experimental developments and uses of silicene and phosphorene have only just started. The stability problem can be overcome by functionalization, ${ }^{61,62}$ or by forming heterostructures. ${ }^{25}$ For example, the design and surface functionalization of Xenes for biomedical applications has been recently reviewed. ${ }^{63}$ In this (bio)context, 2D Xenes have been proposed as biosensors, ${ }^{64,65}$ for bioimaging, ${ }^{66,67}$ as therapeutics, ${ }^{68,69}$ and even as antimicrobials, ${ }^{70}$ and neuroprotective systems. ${ }^{71}$

Commonly, the "MAX" phases have a formula of $M_{n+1} A X_{n}$ where "M" means early $d$-transition metal, "A" represents the main group sp-element (mostly belonging to III A or IV A groups, including $\mathrm{Al}, \mathrm{Ga}$, In, TI, Si, Ge, Sn, Pb, P, As, or S), and "X" indicates $\mathrm{C}$ and/or N. ${ }^{72}$ 2D transition metal carbide and nitride layers (MXenes) have been produced by the selective chemical etching of " $A$ " in MAX phases. Ultrasonication is the primary tool for delaminating, exfoliating and separating MXene sheets of high quality. ${ }^{73}$ In the same way graphene-based materials can be obtained from graphite, the exfoliation of some members of the MAX phase family can be achieve by using hydrofluoric acid solutions and sonication. ${ }^{74}$ As for other $2 \mathrm{D}$ nanomaterials, the surface functionalization of MXenes is possible. ${ }^{75}$ Considering the large family of $2 \mathrm{D}$ materials, MXenes are very young, but they have grown rapidly in the last years. More than 70 different MXenes have been reported and, owing to their large surface area, hydrophilicity, adsorption ability, and high surface reactivity, they have attracted the attention as novel catalysts, for ion batteries, for gas storage media, and as sensors. ${ }^{72}$ Regarding the biomedical applications, MXenes have shown to be promising materials for the fabrication of sensors in environmental analysis and biomedical detection (e.g., gas sensing, detection of $\mathrm{H}_{2} \mathrm{O}_{2}$, and detection of macromolecules and cells). For example, an ultrathin conductive MXene-micropatterned field-effect transistor (FET) device for the fast detection of action potentials in primary neurons was reported. ${ }^{76}$ The FET devices are crucial for the detection of neurotransmitter dopamine through doping effect, caused by the $\pi-\pi$ interaction between dopamine and the electrons from the terminal groups such as $\mathrm{OH}$ and $\mathrm{F}$. Besides, the system could also be used a real-time probe for cultured primary hippocampal neurons, showing an outstanding biocompatibility.

Another class of 2D materials comprises the transition metal oxides (TMOs), ${ }^{77}$ which are composed of oxygen atoms joined to transition metals, being classified in monoxides (MO), dioxides $\left(\mathrm{MO}_{2}\right)$, trioxides $\left(\mathrm{MO}_{3}\right)$, and ternary oxides in which perovskite structure is the most widespread configuration. The type of metal-oxygen bonding varies between highly covalent/metallic to nearly ionic, determining unusual properties of this kind of materials, imparted also by the unique nature of the outer $d$-electrons. TMOs have demonstrated to be suitable candidates for energy-related applications ${ }^{78}$ or for organic electronics. ${ }^{79}$ On the other hand, TMOs 
have also got a lot of attention in the biomedical field. ${ }^{80} \mathrm{MnO}_{2}$ has been for instance used in cancer therapy, ${ }^{81,82}$ and degradable $\mathrm{MoO} x$ has been applied as therapeutic nanoplatforms. ${ }^{83} \mathrm{MoO}_{\mathrm{x}}$ flakes are sufficiently stable in acidic $\mathrm{pH}$ but they are degraded into $\left[\mathrm{MoO}_{4}\right]^{2-}$ at physiological $\mathrm{pH}^{83,84}$

Additional 2D materials include layered double hydroxides (LDHs), ${ }^{85,86}$ metal-organic frameworks (MOFs), ${ }^{87}$ and covalent organic frameworks (COFs). ${ }^{30,88}$ LDHs can be easily obtained by top-down liquid phase exfoliation as 2D nanosheets. ${ }^{89,90}$ This type of nanostructures can be applied in a wide range of fields including energy, catalysis, optics and healthcare. ${ }^{27,91,92}$ Pan et al. demonstrated, for example, how the introduction of LDH layers in polymer matrices can even improve the flame retardancy of polymers. ${ }^{93}$ MOFs, most often synthesized in the form of $3 \mathrm{D},{ }^{94}$ have been recently prepared as $2 \mathrm{D}$ materials by either top-down or bottom-up methods, and can be used as well in different fields such as absorption and separation of toxic substances from gas and liquid, catalysis and environmental or biomedical applications. ${ }^{95}$ 2D MOFs have been successfully applied for instance in X-ray-induced photodynamic therapy of colon cancer. ${ }^{96}$ Finally, COFs have been also prepared as layered materials by mechanical or gas/liquid phase exfoliation. ${ }^{97-99}$ Similarly to LDHs and MOFs, COFs' unique features have made them excellent candidates for a plethora of uses ranging from energy to biomedical sciences. ${ }^{30,100}$ For example, hydrogen and methane storage using 2D COFs have been deeply explored. ${ }^{101,102}$

Overall, the development of 2D layered nanomaterials is ambitious, and the important role of these materials in the industries ${ }^{10}$ and in the biomedical sectors ${ }^{103,104}$ is undoubtable. ${ }^{11,105,106}$ For these reasons, testing and understanding the biodegradability and the impact of $2 \mathrm{D}$ materials in the environment and living organisms is imperative. If nanomaterials are (bio)persistent, their safe use will be under risk unless the body clearance and excretion of administered doses occur. However, if 2D materials are biodegradable, their body or environmental elimination may be superfluous, provided that the degradation by-products will be nontoxic. In spite of this, there are still no data on environmental transformation or biodegradation for the largest variety of the new 2D nanomaterials, being therefore a clear and crucial subject of research.

A series of works have already evidenced that oxidative enzymes (e.g., peroxidases) are able to catalyse the degradation of $2 \mathrm{D}$ materials, ${ }^{107,108}$ in the presence of hydrogen peroxide, following the peroxidase catalytic cycle. ${ }^{109,110}$ These enzymes can be secreted by the immune cells like neutrophils, eosinophils and macrophages. This is the case for human myeloperoxidase (hMPO) or eosinophil peroxidase (EPO). ${ }^{111-113}$ But there are also plant enzymes like horseradish peroxidase (HRP) and fungal enzymes like lignin peroxidase (LiP) capable of the same action. ${ }^{114-117}$ Besides, artificial peroxidases mimicking enzyme known as "DNAzymes" similar to HRP have been recently reported. ${ }^{118}$ These artificial enzymes, which are composed of a guanine rich G-quadruplex (a single-stranded DNA complexed to hemin) resulted efficient in the degradation of GO similarly to HRP.

In a recent highlight, we carefully evaluated the role of the material structural properties in the degradation ability of each specific graphene-based material. ${ }^{108}$ There, we briefly discussed the 
interest of studying the biodegradation possibilities of other 2D materials different from graphene. This review goes ahead in that line, evaluating more in detail the biodegradability issues, describing how the impact of 2D materials in ecosystems is mainly dependent on the type of material, its chemical functionalization (oxidized versus pristine surface chemistry), its aqueous dispersibility and the redox potentials of the enzyme intermediates. We analysed relevant articles centred on biodegradation of 2D materials and the impact of chemistry on this process, expanding further the field by covering the new emerging $2 \mathrm{D}$ materials and the most recent strategies aimed to understand and tune their degradation. This review helps to better understand the biodegradation of 2D materials, and it contributes to elucidate the possible mechanisms of degradation. The design of new artificial enzymes mimicking natural systems that could help to fulfil this purpose is reviewed as well.

To conclude, we hope that this contribution will be useful to design safer 2D-containing composites, biomedical systems and devices. It is time to further advance our understanding by exploring biodegradation of $2 \mathrm{D}$ materials, their functionalized derivatives and their heterostructures. Biodegradation is one of the necessary characteristics for the safe use in vivo of 2D materials. Therefore, only following this strategy, we will be able to identify their most promising biodegradable structures and to apply them in a safe way.

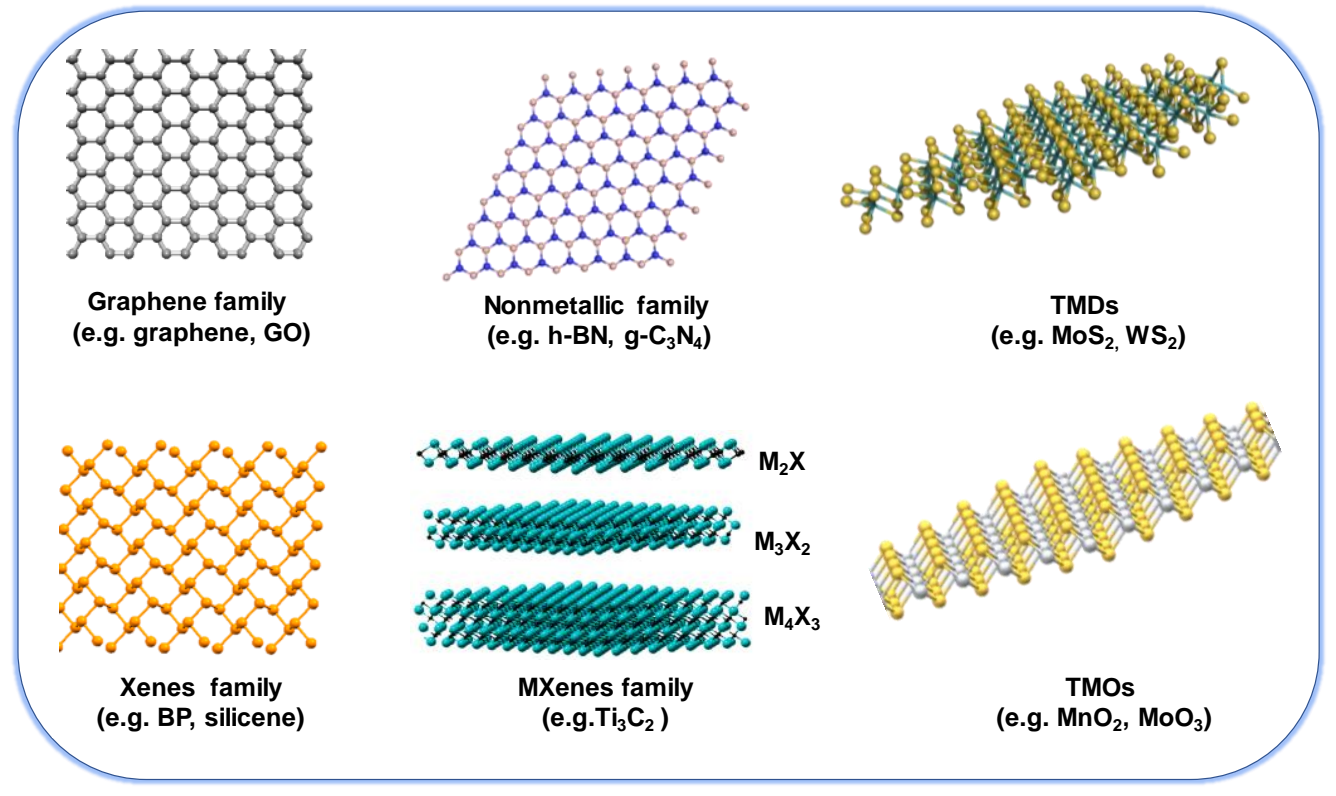

Fig. 1 Molecular structures of representative 2D materials.

\section{Biodegradation of graphene family materials}

GFMs have been widely applied in biomedical fields, including cancer therapy, tissue engineering, biosensing, diagnosis and bioimaging. ${ }^{119-124}$ Because of this wide range of bioapplications, the assessment of their safety has received enormous attention. ${ }^{125-127}$ The study of the biodegradability is one of the steps towards the safe use of GFMs. In this scenario, several research groups have started to look to biodegradation of GFMs, particularly focusing on the peroxidase catalysis and redox reactions. ${ }^{109,128,129}$ The role of the material properties (such as the number of layers, the lateral dimension and the oxidation degree) in the degradation aptitude of each specific GFMs have 
been recently discussed (Fig. 2). ${ }^{108}$

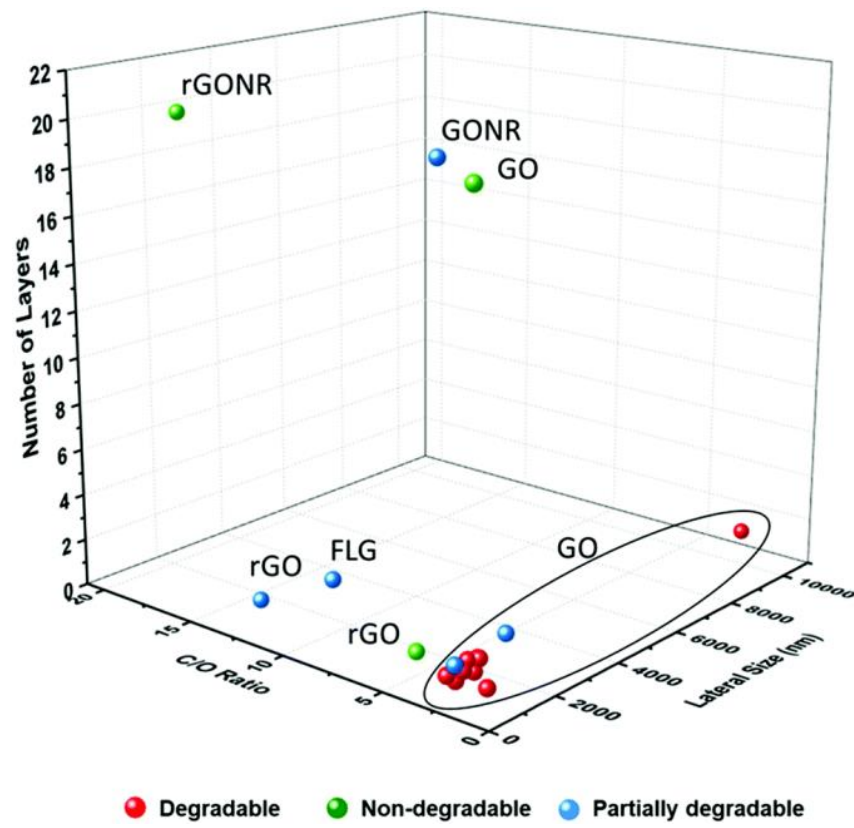

Fig. 2 Classification of biodegradable GFMs based on their later size, number of layers and C/O ratio. Reproduced with permission. ${ }^{108}$ Copyright 2019, the Royal Society of Chemistry.

The available results are very helpful to orient the future applications of GFMs in vitro and in vivo. Usually, Fenton or photo-Fenton redox reactions are the common chemical methods for a GFM efficient degradation, ${ }^{130,131}$ while enzyme-mediated catalytic biodegradations rely on the interactions between an enzyme and GFMs with the assistance of $\mathrm{H}_{2} \mathrm{O}_{2}$ (Fig. 3). ${ }^{10,115,132,133}$ These types of chemical and biochemical processes lead to the oxidation of carbon atoms generating carbon dioxide as final product.
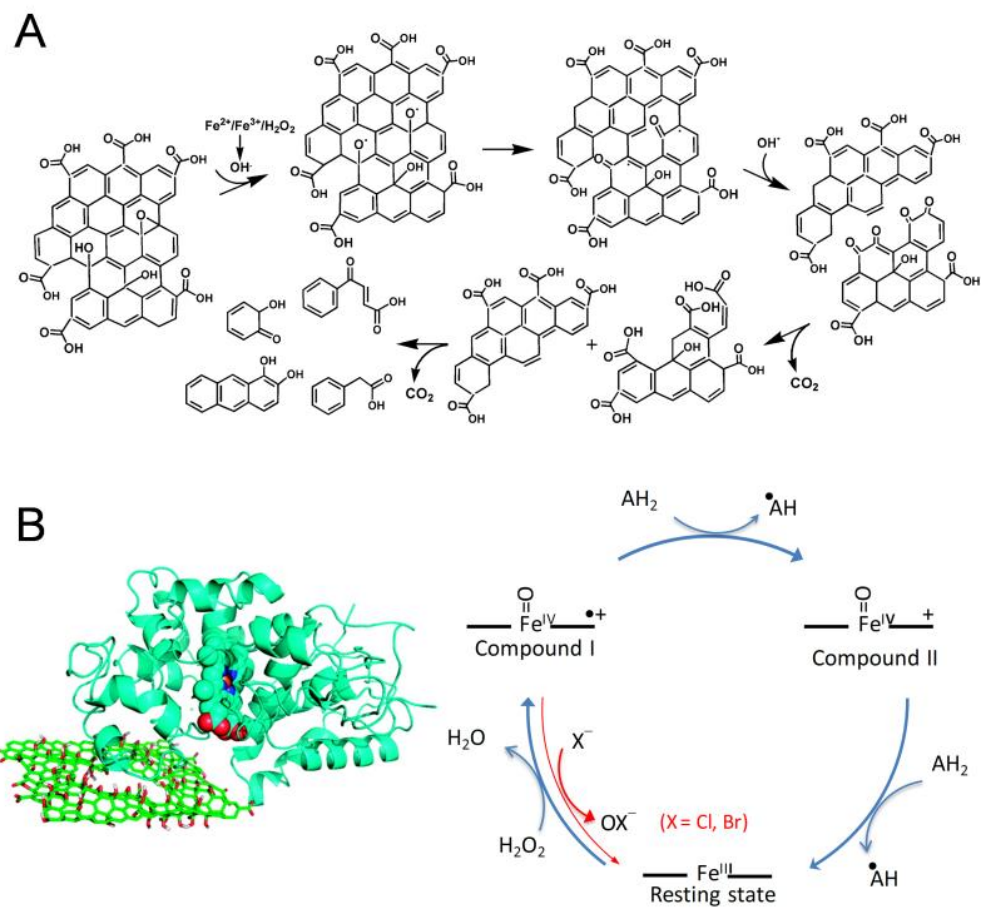

Fig. 3 Biodegradation scheme of GFMs. (A) Degradation process of GO by Fenton reaction $\left(\mathrm{Fe}^{2+} / \mathrm{Fe}^{3+} / \mathrm{H}_{2} \mathrm{O}_{2}\right)$ under UV irradiation leading to final production of $\mathrm{CO}_{2}$. Reproduced with 
permission. ${ }^{130}$ Copyright 2012, the American Chemical Society. (B, left) The interaction between GO and HRP. Reproduced with permission. ${ }^{115}$ Copyright 2011, the American Chemical Society. ( $\mathrm{B}$, right) Peroxidase catalytic cycle of $\mathrm{HRP}, \mathrm{MPO}$ and EPO in the presence of $\mathrm{H}_{2} \mathrm{O}_{2}$, occurring during the degradation of GFMs. Reproduced with permission. ${ }^{110}$ Copyright 2020, the Royal Society of Chemistry.

\subsection{Biodegradation of graphene}

One of the first studies on the degradability of graphene demonstrated that pristine multi-layered graphene can be slowly and partially degraded by redox reactions in the presence of $\mathrm{H}_{2} \mathrm{O}_{2}{ }^{134}$ The process was observed following the changes of the ratio between the $I_{D}$ Raman band (at $\sim 1350$ $\mathrm{cm}^{-1}$ ), associated to the defects of the graphitic structure, and the $\mathrm{I}_{\mathrm{G}}$ band (at $\sim 1580 \mathrm{~cm}^{-1}$ ), representative of the graphitic $\mathrm{sp}^{2}$ structure. Under a relatively low concentration of $\mathrm{H}_{2} \mathrm{O}_{2}$, the $\mathrm{I}_{D} / \mathrm{I}_{G}$ ratio first increased with time of treatment and then decreased again. The trend of this change was attributed to the augmented number of defects on graphene surface after oxidation and subsequent exposure of the underlying pristine graphene layers when the outer layer is damaged. Using a higher concentration of $\mathrm{H}_{2} \mathrm{O}_{2}$, the $\mathrm{I}_{\mathrm{D}} / \mathrm{l}_{\mathrm{G}}$ value decreased faster, and both $\mathrm{D}$ and $\mathrm{G}$ bands almost completely disappeared after $25 \mathrm{~h}$ when the concentration was above $100 \mu \mathrm{M}$.

Alternative to chemical reactions, the environment and living systems rely on biochemical process to degrade exogenous molecules and materials, exploiting natural oxidative enzymes, called peroxidases. Therefore, peroxidase catalytic reactions started to be explored to evaluate their capacity to degrade graphene. Opposite to the general belief that graphene might be nonbiodegradable, like pristine carbon nanotubes (CNTs), ${ }^{135}$ mainly because of lack of functional groups that were demonstrated to play the key role in the interaction and activation of the peroxidases, ${ }^{136}$ it resulted instead that such enzymes can degrade graphene. Highly dispersed single-layer graphene (SLG) and FLG, could be almost completely degraded by human myeloperoxidase (hMPO) up to $40 \mathrm{~h}$ of treatment. ${ }^{111}$ In the cellular systems, hMPO catalytic activity lasts for about $6 \mathrm{~h}$, the life time of the cells secreting the enzyme. Although this short action time, it was demonstrated that this enzyme can degrade CNTs within $24 \mathrm{~h}$ in the lung. ${ }^{107}$ In the context of graphene study, activated immune polymorphonuclear leukocytes, which secret hMPO, are able to degrade SLG and FLG efficiently up to 5 days. This experiment proves that the biodegradability of SLG and FLG likely occurs in vivo, indicating that our immune system can put in place efficient strategies to degrade any type of exogenous materials. These results suggest the safe use of graphene in the biomedical field, as drug delivery system, for instance. In addition to human peroxidases, plant oxidative enzyme like horseradish peroxidase (HRP) were also used to degrade graphene. ${ }^{137}$ However, graphene only was partially degraded after 1 week. This is due to the redox potential of this enzyme, which is lower than that of hMPO. Therefore, not all types of peroxidases can degrade graphene fast and completely. Recently, one study demonstrated that pristine graphene was degraded slowly in blood plasma, producing nanopores and wrinkles in the nanosheets. ${ }^{138}$ This was attributed to the reactive oxygen species (ROS) generated in blood, such 
as $\mathrm{HO}$ and superoxide radicals $\left(\mathrm{O}_{2}^{--}\right)$. These results highlight how graphene can be degraded in vitro and in vivo, supporting its biosecurity.

\subsection{Biodegradation of graphene oxide}

GO is probably the most studied member of the GFMs as it possesses several advantages compared with graphene, like a high dispersibility and chemical reactivity, which endow GO with great potential in biomedicine. ${ }^{139-141}$ Since GO has a very high oxidation degree and more defect sites than graphene, it is degraded much easier and faster than graphene, resulting safer for this characteristics. ${ }^{138}$ Several studies have addressed the biodegradability of GO. Photo-Fenton reaction can be considered the most exploited chemical method to degrade GO. ${ }^{142}$ For example, $\mathrm{GO}$ underwent morphological changes during the photo-Fenton reaction at $\mathrm{pH} 4$, and it was transformed into graphene quantum dots. ${ }^{130}$ From the point of view of the mechanism, the degradation of GO starts at the carbon atoms connected with the oxygen-containing functional groups, following C-C bond break. Therefore, a high content of oxygen atoms contributes to favour the degradation of GO. During the degradation process, the structures of generated by-products consist of oxidized polycyclic aromatic hydrocarbons. Eventually, GO degrades to carbon dioxide and $\mathrm{H}_{2} \mathrm{O}$ when $\mathrm{pH}$ value is below $3 .{ }^{143}$ This indicates that $\mathrm{pH}$ value plays a key role in the final degraded products. Alternatively to the photo-Fenton reaction, the treatment with hypochlorite can also degrade GO quickly, which provides a new way of degradation. ${ }^{144}$

Like we observed for graphene, photo-Fenton reaction or hypochlorite oxidisation are not the ways by which GO degrades in vivo. In a living system, we can therefore imagine that the biodegradation of GO undergoes via the catalytic action of peroxidases. The ability of hMPO to degrade GO with different degree of oxidation, leading to a variable dispersibility in water, was assessed in phosphate buffer rich in $\mathrm{NaCl}$ and in the presence of $\mathrm{H}_{2} \mathrm{O}_{2} \cdot{ }^{112} \mathrm{hMPO}$ could completely degrade highly dispersed GO, while it failed to degrade the most aggregated GO. This means that hydrophilicity, available negative surface charge and colloidal stability have significant effects on GO enzymatic degradation. The results obtained by this study provide a helpful guidance to design degradable GO-based materials. In another work, big-size (micrometre range lateral dimension) and small-size (nanometre range lateral dimension) GO could be degraded directly by neutrophils after their degranulation, and the degradation products were proved to be non-cytotoxic and nongenotoxic to the human lung BEAS-2B cell line. ${ }^{145}$ Alternative to hMPO, recombinant eosinophil peroxidase (EPO) enzyme secreted by human eosinophils also showed efficient degradation ability of $\mathrm{GO}$ with different degrees of oxygen functional groups in the presence of a low concentration of $\mathrm{H}_{2} \mathrm{O}_{2}$ and $\mathrm{NaBr} .{ }^{110}$ The content of oxygenated defects has an obvious impact on the biodegradation rate of GO by EPO, which is similar to hMPO mediated catalytic degradation. However, the degradation speed of EPO ( $\sim 90 \mathrm{~h}$ ) is lower than hMPO ( $24 \mathrm{~h})$, certainly due to the difference of the redox potentials of generated reactive intermediates. The redox potential of hMPO $(\sim 1.16 \mathrm{eV})$ is only slightly higher than that of EPO $(\sim 1.10 \mathrm{eV})$, but hMPO can produce stronger oxidant species (e.g., $\mathrm{HOCl}$ ) than EPO (e.g., $\mathrm{HOBr}$ ), that justify a quicker degradation of $\mathrm{GO}$ by MPO catalysis. 
Furthermore, HRP could also catalyse the oxidation of GO. The pioneer study of Star and coworkers demonstrated how HRP is able to form quite regular holes on the basal plane of GO in the presence of low concentrations of $\mathrm{H}_{2} \mathrm{O}_{2} \cdot{ }^{115}$ In the same study, HRP failed to oxidize reduced GO. The authors found that HRP was preferentially bound to the basal plane rather than the edge of GO by computational docking analysis. It resulted that the heme active site of HRP is in closer proximity to $\mathrm{GO}$ than reduced $\mathrm{GO}$, facilitating the oxidation of former.

It is well-known that DNAzymes, composed of supramolecular guanine-rich G-quadruplexes, display peroxidase activity mimicking HRP. ${ }^{118}$ A DNAzyme consisting of a PS2.M-hemin complex was demonstrated to oxidize and degrade GO as an alternative to natural HRP. Although the degradation rate was relatively low, similar to HRP (degradation period $\sim 30 \mathrm{~d}$ ), this strategy opens many possibilities for the design of better artificial oxidative enzymes for the biodegradation of GFMs and other new 2D materials. Very limited remain the studies exploring the biodegradation of GFMs by environmental microorganisms like bacteria and fungi. One example has reported the biodegradation of GO by bacterium Labrys sp. WJW, while another described the transformation of GO by white rot fungus Phanerochaete chrysosporium, opening positive perspectives in GO disposal. ${ }^{146,147}$

Besides the last two examples, all data described above demonstrate the degradation of GO in test tube or in vitro. To assess the biodegradation of GO in vivo, the biotransformation of GO in blood was observed, which is fundamental to assess a safe use of this material. ${ }^{148}$ The results reported in this study suggested that the biodegradation and the formation of the biological corona on GO occurred simultaneously in blood plasma and could influence GO toxicity. Reactive species $\mathrm{HO}$, but not $\mathrm{O}_{2}{ }^{--}$, seems to play a dominant role in the degradation of $\mathrm{GO}$ in blood, with a mechanism similar to the photo-Fenton reaction mediated degradation. ${ }^{142}$ In summary, GO possesses a better biodegradability than graphene, likely resulting in safer in the different fields of applications.

\subsection{Biodegradation of other GFMs}

Besides graphene and GO, the biodegradation of other GFMs (e.g. graphene quantum dots, oxidized graphene nanoribbons, and 3D graphene scaffolds) have been also studied. The different studies provide promising evidence about the biosecurity of GFMs. The degradation of oxidized and reduced graphene oxide nanoribbons (GONRs and rGONRs) was evaluated using the fungal enzyme LiP with and without the assistance of veratryl alcohol (VA is an electron transfer mediator and a secondary metabolite of white rot fungi). ${ }^{116}$ Within $96 \mathrm{~h}$, in the presence of $\mathrm{H}_{2} \mathrm{O}_{2}$ and VA, GONRs and rGONRs were degraded completely and partially by LiP, respectively. The degradation rate decreased obviously when VA was removed by the solution. Therefore, VA is an essential factor in the degradation of GONRs and rGONRs by LiP catalysis.

Graphene quantum dots (GQDs) are an emerging type of OD carbon material, and possess an atomically thin graphitic plane (typically 1 or 2 layers) usually with the size $<10 \mathrm{~nm} .{ }^{149}$ They have been develop as multifunctional platforms for applications in bioimaging, biosensing, and 
therapy. ${ }^{150}$ The hMPO- and hEPO-mediated biodegradation of GQDs was observed after a few hours and became more obvious after a few days. ${ }^{151}$ Molecular dynamics simulations showed closed interactions between the enzymes and GQDs, ensuring a good degradation efficiency. Furthermore, the biodegradation of 3D graphene scaffolds prepared by a deposition-etching process, with high porosity and specific surface area for tissue engineering was also studied by culturing the material with HepG2 hepatocarcinoma cells. ${ }^{152,153}$ The 3D graphene scaffold showed a 2-step oxidative biodegradation process, consisting first on the disruption of the single-layer domains and the peeling off of smaller graphitic particles from the surface of the scaffold, followed by the decomposition and gradual degradation of the other graphitic flakes.

To promote the biodegradation of graphene, a carboxylated graphene, corresponding to an oxidized derivative of graphene, well-dispersed in water similarly to GO, was prepared to study the role of defects and functional groups on biodegradation. Confocal Raman imaging was used to characterize the macrophage-mediated biodegradation of this carboxylated graphene. ${ }^{154} 3 \mathrm{D}$ images of characteristic Raman signatures of the material were obtained from different mouse organs allowing to identify the gradual change and the structural disorders. The changes of another characteristic band of graphene materials related to defects, called D' (at $\sim 1620 \mathrm{~cm}^{-1}$ ), were followed together with the evolution of the $I_{D} / l_{G}$ ratio. Both values increased, while the overall intensity of the bands decreased with time in different tissues. Interestingly, the biodegradation of this type of graphene was prominent in spleen over for 3 months, attributed to the action of the phagocytic immune cells. However, almost no oxidation of pristine graphene happened up to 6 weeks in the lungs, ${ }^{114}$ which means that carboxylation can promote the degradation of graphene.

In conclusion, many GFMs can be degraded by enzymatic and chemical redox reactions (Fig. 4). The assessment of biodegradability can further promote applications, and it also helps to increase the confidence in the biosafety of GFMs.

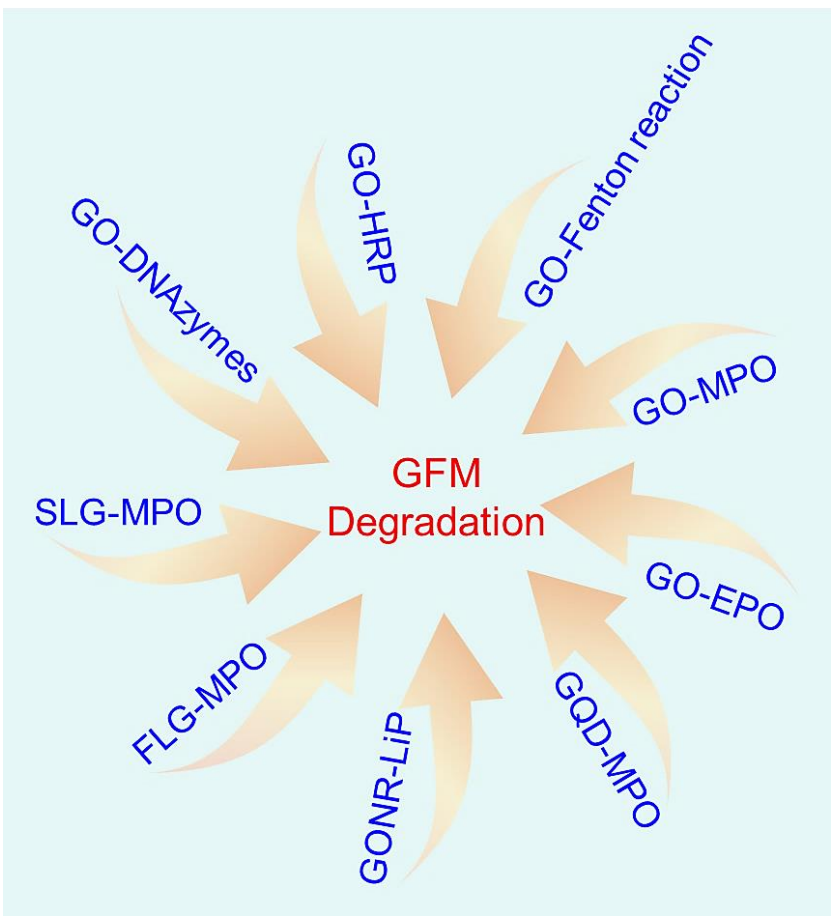

Fig. 4 Illustration of the typical GFM degradation pathways followed by different enzymatic and 
chemical reactions.

\subsection{Biodegradation of carbon nanotubes}

Although CNTs are considered within the family of graphitic carbon nanomaterials, they are not 2D. However, we have decided to describe them because their degradation have been started to be studied before GFMs and many experiments have been designed on that protocols. CNTs are composed of graphene sheets and they are structurally divided into single-walled (SWCNTs) and multi-walled carbon nanotubes (MWCNTs). Due to the increased demand and the extensive applications, the biocompatibility and the biodegradation of CNTs raised significant concerns. ${ }^{155,156}$ The biodegradability of CNTs reduces the side effects and makes CNTs better eliminated from the body, increasing their biosecurity.

It has been demonstrated that CNTs can be oxidized slowly and partially by commonly used oxidants like $\mathrm{NaOCl}, \mathrm{HNO}_{3}$, and $\mathrm{H}_{2} \mathrm{O}_{2} \cdot{ }^{157-159} \mathrm{Fe}^{2+} / \mathrm{Fe}^{3+}$-mediated Fenton reaction completely degrades SWCNTs in $\sim 10$ days. ${ }^{160}$ Varied peroxidases (such as HRP, hMPO, EPO, LiP, and manganese peroxidase) were used to degrade CNTs. ${ }^{107,161-165}$ For example, HRP can catalyse the biodegradation of oxidized SWCNTs, ${ }^{162,166}$ and the oxidative biodegradation of SWCNTs was triggered using LiP. ${ }^{164}$ SWCNT dispersions were also degraded by hMPO, in 24 h. ${ }^{107}$ In comparison to the action of HRP, the synergetic effects of generated hypochlorite $(\mathrm{HOCl})$ and the reactive intermediates in $\mathrm{MPO} / \mathrm{H}_{2} \mathrm{O}_{2} / \mathrm{Cl}^{-}$system promote $\mathrm{CNT}$ degradation more efficiently than the $\mathrm{HRP} / \mathrm{H}_{2} \mathrm{O}_{2}$ system. ${ }^{167}$

Macrophages, recruited in the lung after pulmonary exposure to CNTs, are able to degrade functionalized SWCNTs by a superoxide/peroxynitrite oxidative process. ${ }^{168,169}$ SWCNTs with defect sites are more prone to be biodegraded by macrophages, ${ }^{170}$ and the functionalization of SWCNTs with IgG promotes MPO release and $\mathrm{ONOO}^{-}$formation in zymosan-stimulated macrophages, subsequently contributing to the higher degradation degree. ${ }^{171}$ PEGylated SWCNTs are able to activate neutrophils to increase the production of $\mathrm{HOCl}$, leading to a stronger oxidative degradation. ${ }^{172}$ Furthermore, photothermal imaging is a visual and practical technology that allowed to assess the degradation level of functionalized MWCNTs in primary glial cells. ${ }^{173}$

The study of the clearance and degradation behaviour of CNTs in vivo is very important to assess their biosecurity. ${ }^{174}$ Several studies have demonstrated that functionalized CNTs showed no apparent toxicity in vivo, and could be excreted. ${ }^{175-177}$ However, impaired clearance and enhanced pulmonary inflammatory/fibrotic response to CNTs happened in MPO-deficient mice, meaning that MPO plays a vital role in the degradation process in vivo. ${ }^{178}$ Furtherlore, Diels-Alder functionalized CNT membranes for bone tissue engineering could be degraded easier than membranes containing non-functionalized CNTs, likely mediated by the oxidation-induced MPO in neutrophil and macrophage inflammatory conditions. ${ }^{179}$ In conclusion, certain types of CNTs are biodegradable particularly those chemically functionalized, as the functional groups introduce on the surface of the tubes regulate the biodegradation and the toxicity in vivo. 


\section{Biodegradation of other $2 \mathrm{D}$ materials}

Beyond graphene and its derivatives, numerous 2D family materials have been explored and applied in the biomedical fields. ${ }^{180}$ Based on their different properties, 2D materials are designed and chemically modified for specific applications, such as drug delivery, cancer diagnosis and therapy, bioimaging, biosensing, cell differentiation, and tissue engineering. ${ }^{181-183}$ Assessing the biodegradability of 2D materials is fundamental for their translation into future clinical applications. ${ }^{184}$ It has been reported so far that 2D materials are generally absorbed or eliminated after degradation by metabolic or enzymatic actions. These processes transform the structure and composition of $2 \mathrm{D}$ materials into ultra-small particles or soluble ions. ${ }^{108}$ The investigation of the biodegradability of $2 \mathrm{D}$ materials is fundamental to assess their biosecurity and to understand their behaviour during or after their biological actions in vivo. In this section, the degradation of Xenes family materials, MXenes family materials, transition metal dichalcogenides, transition metal oxides, non-metallic materials and other $2 \mathrm{D}$ materials will be discussed in detail.

\subsection{Xenes' family materials}

Monoelemental 2D materials belonging mainly to the periodic table group IV and V, called Xenes, have attracted a wide attention due to their new and unique properties. Xenes are considered the next generation biomaterials, and they start to be widely applied in biomedicine, for photothermal therapy, diagnosis, drug delivery and imaging. ${ }^{63}$ Therefore, the study of their biosecurity and biodegradability is very important. The low stability of pristine Xenes provides huge advantages, particularly because of their intrinsic biodegradability. Black phosphorus is currently the most studied 2D Xene material in the biomedical domain. ${ }^{185-189}$ It has been proved that $\mathrm{BP}$ can be easily oxidized by $\mathrm{H}_{2} \mathrm{O}_{2}$, and can be degraded by $\mathrm{O}_{2}$ dissolved in water or by $\mathrm{O}_{2} /$ light system (Fig. 5). ${ }^{190-195}$ These conditions are easy to be met into cells and tissues, posing the bases for the biodegradation of BP in vitro and in vivo. Furthermore, the degradation process of $\mathrm{BP}$ is correlated to the electronic structure, explained by the transfer of electrons to surface physisorbed $\mathrm{O}_{2}$ molecules leading to the layer-dependent oxidation of $\mathrm{BP}$, and is $\mathrm{pH}$ dependent. ${ }^{196,197}$ For materials science applications, it has been demonstrated that chemical modifications and inclusion into composites can enhance the stability of BP. ${ }^{198-200}$ Importantly, the final degradation product of $\mathrm{BP}$ consist of $\mathrm{PO}_{4}{ }^{3-}$ ions, which are nontoxic not only to cells or organs, but also to the environment. ${ }^{201,202}$ Therefore, BP possesses high potential for further secure applications. 

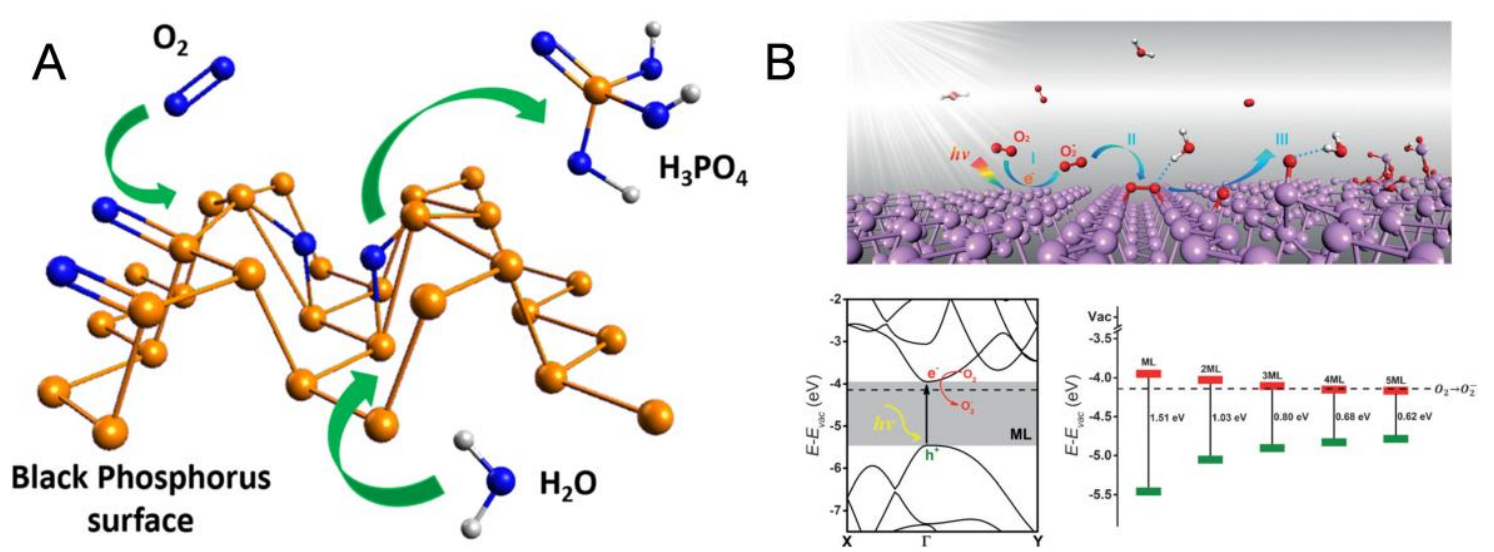

Fig. 5 (A) Oxidative degradation of $\mathrm{BP}$ by $\mathrm{O}_{2} / \mathrm{H}_{2} \mathrm{O}$ system. Reproduced with permission. ${ }^{194}$ Copyright 2019, the American Chemical Society. (B) Oxidative degradation of BP by $\mathrm{O}_{2} /$ light system. Reproduced with permission. ${ }^{195}$ Copyright 2016 , Wiley.

Besides BP, other Xenes are widely exploited. 2D antimonene nanosheets (AMNSs) have been applied as photonic nanomedicines for multimodal-imaging-guided cancer theranostics. ${ }^{66}$ AMNSs could be degraded in water, and oxygen dissolved in water can accelerate the degradation remarkably, indicating that the biodegradation of AMNSs follows an oxidation pathway. It has been reported that in vivo, AMNSs are cleared from mouse body by metabolic degradation after 30 days, letting to consider antimonene as a safe material. ${ }^{66,203}$ However, many of newly synthesised Xenes materials, such as tellurene, ${ }^{69}$ borophene, ${ }^{67}$ and bismuthene, ${ }^{204}$ have been initially applied in the biomedical field, but their biodegradability has been not assessed yet.

According to the current results, we can say that the degradation of Xenes materials is mainly following a process of oxidation promoted by $\mathrm{O}_{2}$ or $\mathrm{H}_{2} \mathrm{O}_{2}$. The presence of these molecule inside the cells and tissues renders Xenes quite safe materials for in vivo uses, and clinical applications.

\subsection{Mxenes' family materials}

Mxenes' materials are another type of 2D materials that have attracted enormous attention from their discovery in 2011.205 Mxenes consist of transition metal carbides, nitrides, and carbonitrides with a typical formula of $M_{n+1} X_{n}$ (M: early $d$-transition metal; $X$ : carbon and/or nitrogen). ${ }^{206}$ Due to the distinctive properties, Mxenes have been widely applied in varied fields, and biomedicine is one very important and attractive area of exploitation. ${ }^{207}$ Therefore, it is becoming necessary and urgent to assess the biodegradability potential and biosafety of these materials.

Titanium carbide $\left(\mathrm{Ti}_{3} \mathrm{C}_{2}\right)$ Mxene has been applied, for example, in cancer therapy due to its excellent photothermal efficiency. ${ }^{208,209}$ To improve the dispersibility and the efficiency, $\mathrm{Ti}_{3} \mathrm{C}_{2}$ is usually chemically modified and combined with other materials. ${ }^{210,211}$ However, there is no report about the degradability of $\mathrm{Ti}_{3} \mathrm{C}_{2}$ Mxene likely due to its high stability. Titanium nitride (TiN) and 
tantalum carbide $\left(\mathrm{Ta}_{4} \mathrm{C}_{3}\right)$ Mxenes also possess properties similar to $\mathrm{Ti}_{3} \mathrm{C}_{2} \cdot{ }^{212,213}$ Recently, alternative biodegradable Mxenes have been developed for uses in nanomedicine. Polyvinyl alcohol modified ultrathin molybdenum carbide $\left(\mathrm{Mo}_{2} \mathrm{C}-\mathrm{PVA}\right)$ Mxene exhibits high biocompatibility and fast degradability, showing high efficiency for photonic tumour hyperthermia. ${ }^{214}$ Nanoflakes of $\mathrm{Mo}_{2} \mathrm{C}$-PVA Mxene can be degraded in the presence of water and water-dissolved oxygen, while the addition of $\mathrm{H}_{2} \mathrm{O}_{2}$ accelerates the degradation process. Consequently, we can conclude that $\mathrm{Mo}_{2} \mathrm{C}$-PVA Mxene is probably easily degraded inside cells or tissues. $\mathrm{Mo}_{2} \mathrm{C}$ Mxene is transformed into soluble innocuous $\mathrm{MoO}_{4}{ }^{2-}$. Alternatively, $\mathrm{PEG}$ modified tungsten nitride (PEG-WN) Mxene also undergoes an oxidative degradation. It has been reported that most of PEG-WN could be excreted in vivo within one week, following its oxidation to water-soluble small molecular species (such as ammonium metatungstate hydrate). ${ }^{215}$ Interestingly, nanosheets of PVP modified niobium carbide ( $\mathrm{Nb}_{2} \mathrm{C}-\mathrm{PVP}$ ) Mxene can be degraded by hMPO in the presence of $\mathrm{H}_{2} \mathrm{O}_{2}$ (Fig. 6). ${ }^{216}$ In view of the data reported in the literature, we can conclude that Mxenes' materials are biocompatible and biodegradable and they possess a great potential in biomedicine.

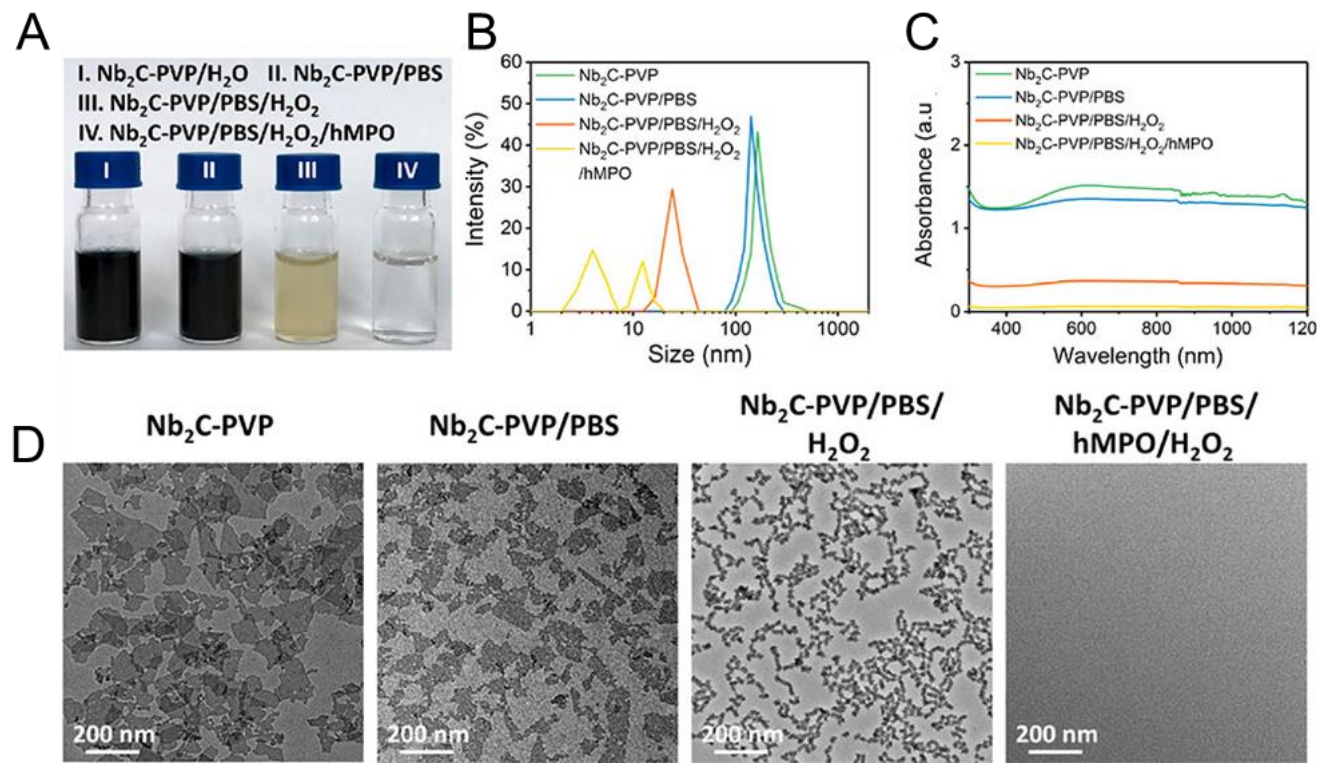

Fig. 6 Biodegradation of $\mathrm{Nb}_{2} \mathrm{C}-\mathrm{PVP}$ Mxene by hMPO catalysis in PBS in the presence of $\mathrm{H}_{2} \mathrm{O}_{2}$. (A) Colour change, (B) size change and (C) absorbance spectra changes of $\mathrm{Nb}_{2} \mathrm{C}$-PVP Mxene under different conditions. (D) Morphology change of $\mathrm{Nb}_{2} \mathrm{C}$-PVP Mxene under different conditions. Reproduced with permission. ${ }^{216}$ Copyright 2017, American Chemical Society.

\subsection{Transition metal dichalcogenides}

TMDs are within the first 2D materials that have been explored in biomedicine. ${ }^{217-220}$ The reference TMD is $1 \mathrm{~T}$ phase $\mathrm{MoS}_{2}$, which is easily degraded in phosphate buffer saline (PBS) after 7 days, being oxidized into water-soluble molybdenum oxide species (e.g., $\mathrm{MoO}_{4}{ }^{2-}$ ). ${ }^{221,222}$ It is worth noting that acidic $\mathrm{pH}$ accelerate $\mathrm{MoS}_{2}$ degradation, favouring its applications for cancer therapy, due to the acidic microenvironment in tumour tissues. Our group found that $\mathrm{MoS}_{2}$ could be quickly degraded after $24 \mathrm{~h}$ by the $\mathrm{hMPO} / \mathrm{H}_{2} \mathrm{O}_{2} / \mathrm{NaCl}$ system. ${ }^{113}$ On the basis of 
this finding, we can hypothesize that $\mathrm{MoS}_{2}$ would show faster degradation in vivo. In this context, Liu and co-workers have demonstrated that $\mathrm{MoS}_{2}$ can be biodegraded and excreted relatively faster than $\mathrm{WS}_{2}$ and $\mathrm{TiS}_{2}$ after intravenous injection. Therefore, $\mathrm{MoS}_{2}$ can be considered particularly promising for further biomedical applications. Although not studied, it seems that protein corona, likely formed in the blood stream, does not hinder the biodegradation. ${ }^{223}$ In addition, covalent functionalization would increase the stability of $\mathrm{MoS}_{2}$ by stabilising the 1T phase compared to the pristine $\mathrm{MoS}_{2}$. Therefore, by chemical modifications it is possible to tune the degradation rate according to the corresponding application.

Besides dichalcogenides, it has been demonstrated that other metal containing sulphides like tetragonal $\mathrm{Fe}_{3} \mathrm{~S}_{4}$ can effectively accumulate in the tumour under magnetic targeting, and gradually biodegrade into particles of few nanometre diameter made of $\gamma$-FeOOH over three weeks by releasing $\mathrm{Fe}$ ions. ${ }^{224}$ The degraded product would be effectively excreted from the body after exerting their therapeutic effect. Other nanomaterials like $\mathrm{SnS}$ and $\mathrm{MoTe}_{2}$ showed a NIR light-triggered degradable phenomenon through metal element oxidation. ${ }^{225,226}$ The degradation products of $\mathrm{MoTe}_{2}$ contain $\sim 21 \%$ of $\mathrm{Mo}(\mathrm{V})$ and $\sim 79 \%$ of $\mathrm{Mo}(\mathrm{VI})$, which confirms that most of $\mathrm{Mo}(\mathrm{V})$ is oxidized to $\mathrm{Mo}(\mathrm{VI})$ under the $\mathrm{NIR}$ irradiation-mediated degradation. However, the biodegradability studies of many other TMDs and transition metal sulphides and selenides (e.g., InSe, $\mathrm{MoSe}_{2}, \mathrm{Bi}_{2} \mathrm{~S}_{3}, \mathrm{TaS}_{2}$ and $\mathrm{TiS}_{2}$ ) are missing although they have shown promising results as biomedical tools. ${ }^{227-231}$

\subsection{Transition metal oxides}

2D Transition metal oxides (TMOs) have also gotten a lot of attention in various fields, including the biomedical. ${ }^{80}$ For example, $2 \mathrm{D} \mathrm{MnO}_{2}$ has been used in cancer therapy and diagnosis. $\mathrm{MnO}_{2}$ nanosheets can react with glutathione (GSH), and be reduced to $\mathrm{Mn}^{2+}$ ions (Fig. 7). The reaction between $\mathrm{MnO}_{2}$ and $\mathrm{GSH}$ not only consumes intracellular $\mathrm{GSH}$, but also causes the biodegradation of the nanosheets. ${ }^{232}$ Exploiting this process, $\mathrm{MnO}_{2}$ has been explored as ultrasensitive $\mathrm{pH}$-triggered cancer theranostics, for cancer treatment. The Fenton-like reaction of $\mathrm{Mn}^{2+}$ ions converts $\mathrm{H}_{2} \mathrm{O}_{2}$ into hydroxyl radical, for intracellular glutathione detection, as mediator signal amplifier of down-regulated intracellular microRNA. ${ }^{233-236}$

Additional TMO materials like $\mathrm{Co}_{3} \mathrm{O}_{4}$ flat nanoprisms and $\mathrm{MoO}_{\mathrm{x}}$ [e.g., $\mathrm{H}_{\mathrm{x}}\left(\mathrm{Mo}_{\mathrm{x}}\right)\left(\mathrm{Mo}^{\mathrm{VI}_{1-\mathrm{x}}}\right) \mathrm{O}_{3}$ ] nanosheets have been recently studied. $\mathrm{Co}_{3} \mathrm{O}_{4}$ is biodegradable in the presence of $\mathrm{H}_{2} \mathrm{O}_{2}$ in acidic conditions via a redox reaction. $\mathrm{Co}^{3+}$ ions released from $\mathrm{Co}_{3} \mathrm{O}_{4}$ are able to convert $\mathrm{H}_{2} \mathrm{O}_{2}$ into hydroxyl radicals to kill cancer cells through a Fenton-like reaction. ${ }^{237} \mathrm{MoO}_{x}$ nanosheets are instead relatively stable in acidic $\mathrm{pH}$ and are degraded into $\left[\mathrm{MoO}_{4}\right]^{2-}$ at physiological pH. ${ }^{83,84,238,239}$ Furthermore, $\mathrm{MoO}_{x}$ nanosheets are able to convert $\mathrm{H}_{2} \mathrm{O}_{2}$ into cytotoxic superoxide radicals leading to cancer cell death. Due to the relatively good stability in tumour microenvironment to cause cancer cell death by combination of photothermal therapy (PTT) and chemodynamic therapy (CDT), and the fast degradability in normal tissues, $\mathrm{MoO}_{\mathrm{x}}$ nanosheets possess great advantages for future clinical applications. 


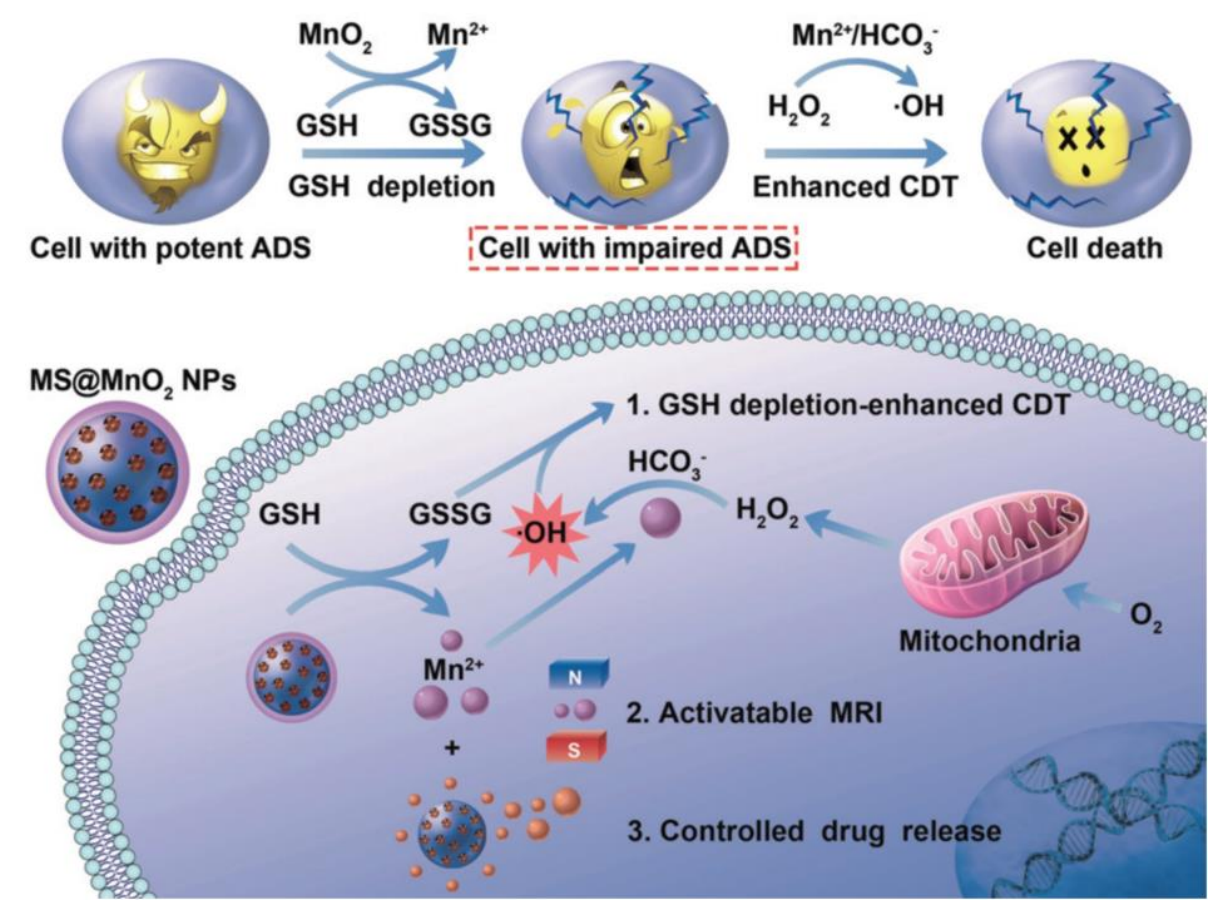

Fig. 7 Biodegradation of $\mathrm{MnO}_{2}$ by intracellular $\mathrm{GSH}$ with the synergistic effect of $\mathrm{Mn}^{2+}$ ions mediated by Fenton-like reaction. Reproduced with permission. ${ }^{232}$ Copyright 2018, Wiley.

\subsection{Non-metallic 2D materials}

Non-metallic 2D materials mainly include $\mathrm{hBN}$ and graphitic carbon nitride $\left(\mathrm{g}-\mathrm{C}_{3} \mathrm{~N}_{4}\right)$. These materials were demonstrated to display a relatively high biocompatibility, and were explored for biomedical applications. ${ }^{240-244}$ However, the biodegradability of $h B N$ and g- $C_{3} N_{4}$ nanosheets is little studied, likely because of their high chemical stability and strong resistance to oxidation.

Our group evaluated the biodegradability of hBN nanosheets by comparing the catalytic activity of HRP and hMPO to the photo-Fenton reaction. ${ }^{114}$ The results showed that hBN flakes underwent only a partial oxidation using hMPO after $35 \mathrm{~h}$ of treatment, while HRP failed to degrade hBN up to 60 days (Fig. 8). Nearly complete degradation occurred instead in the conditions of the photo-Fenton reaction during $100 \mathrm{~h}$. This study evidenced that hBN possesses higher intrinsic stability compared to GFMs.

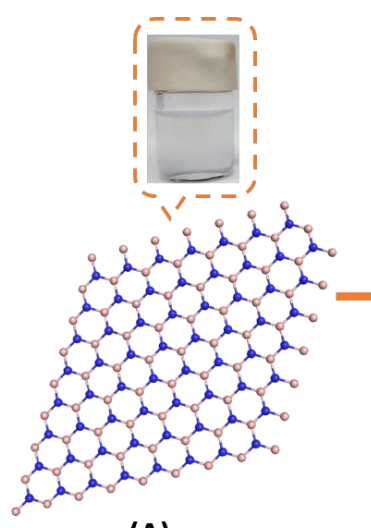

(A)

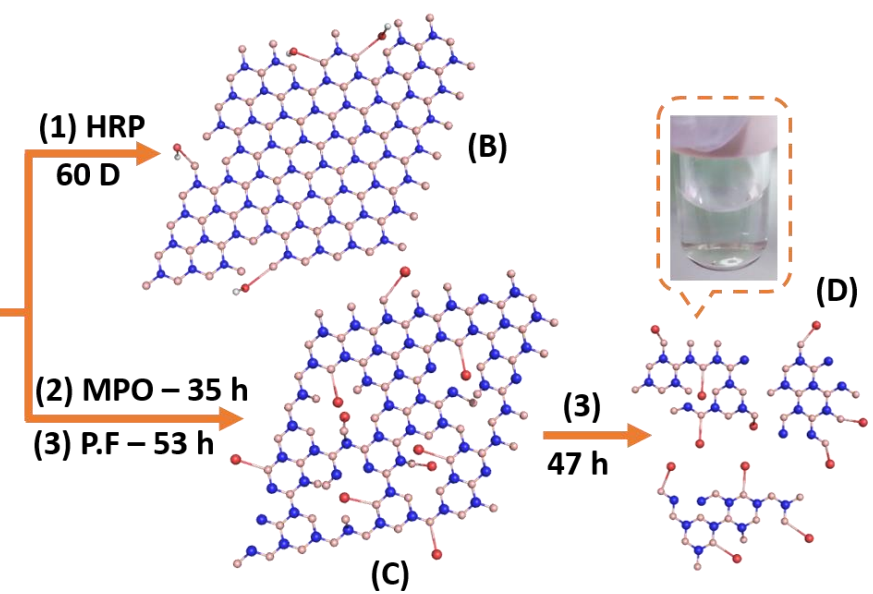

Fig. 8 The biodegradation of hBN by hMPO and HRP catalysis and photo-Fenton reaction. MPO catalysis (2) and Fenton reaction (3) both can degrade hBN efficiently, and HRP catalysis (1) 
fails to degrade hBN. Reproduced with permission. ${ }^{114}$ Copyright 2018, Wiley.

Generally, $\mathrm{g}-\mathrm{C}_{3} \mathrm{~N}_{4}$ is very difficult to degrade. However, when it is in the form of quantum dots with diameter of 2 to $6 \mathrm{~nm}$, it can be degraded within $24 \mathrm{~h}$ inside cells. ${ }^{245}$ Furthermore, disulfide bonds present as defects in the $\mathrm{g}-\mathrm{C}_{3} \mathrm{~N}_{4}$ framework because $\mathrm{NH}_{4} \mathrm{HSO}_{4}$ is used as a critical adjuvant during the preparation process could endow $g-\mathrm{C}_{3} \mathrm{~N}_{4}$ nanosheets with partial biodegradability, permitting to the reducing responsive intracellular compartments to break disulfide bond. ${ }^{246}$ Inversely, bulk $\mathrm{g}-\mathrm{C}_{3} \mathrm{~N}_{4}$ is very resistant to degradation. These results demonstrate that size and chemical modifications are playing an important role to improve g$\mathrm{C}_{3} \mathrm{~N}_{4}$ biodegradation.

\subsection{Other 2D materials}

In addition to the different classes of 2D materials that we have considered so far in this review, there are also other families that are emerging for different types of applications and that deserve attention about their degradability behaviour and safety. These 2D materials are layered LDHs, ${ }^{85,86}$ MOFs, ${ }^{87}$ and COFs. ${ }^{30,88}$

In the case of LDHs, nanosheets containing conjugated $\mathrm{Fe}^{2+}$ ions and stabilized by PEGylation were used as therapeutic nanocatalysts for efficient tumour ablation by triggering a localized Fenton reaction, which is attributed to the efficient biodegradation of this system at $\mathrm{pH}$ value below 6.5 in the specific tumour microenvironment. ${ }^{247}$ In a different work, the microbial biodegradation of poly(3-hydroxybutyrate)/layered double hydroxide composite has been reported. ${ }^{248}$ In this study, it was found that, while the addition of different percentages of LDH to poly(3-hydroxybutyrate)-based films enhances their mechanical properties, the differences on bacterial degradability of these organo-modified LDHs are negligible.

In the case of MOFs, a biocompatible and biodegradable Cu-TCPP(Fe) MOF [TCPP, tetrakis(4-carboxyphenyl) porphyrin] loaded with cisplatin was designed for cancer therapy application. Following the delivery of the drug, the anticancer efficiency of the system was enhanced by the Fenton reaction of $\mathrm{Cu}$ ions released after biodegradation. ${ }^{249}$ In another study, platinum-based Sm-TCPP-Pt MOF nanosheets ware developed and used as a degradable platform to treat cancer by mitochondrion-targeting and oxygen self-supplier photodynamic therapy. ${ }^{250}$ Finally, few biodegradable 2D COFs were prepared by condensation of appropriate molecular building blocks, connected through reversible dynamic bonds. ${ }^{30,251}$ The reversible covalent bonds are able to maintain their structure in normal conditions but to break under specific stimuli such as low $\mathrm{pH} .{ }^{252}$ COFs are stable enough to preserve their structure before reaching the target tissues and biodegrade in the cancer microenvironment. ${ }^{88}$ For instance, a 2D nanosized COF composed of 1,4-benzendiboronic acid and (3-aminopropyl) triethoxysilane, coated with polydopamine, and loaded with indocyanine green has been used in cancer immunotherapy, ${ }^{253}$ while a cyanine IR783 stabilized COF nanosheets, made of 2,3,6,7,10,11hexahydroxytriphenylene and 5,15-bis(4-boronophenyl)-porphyrin, was developed for PTT and 
chemotherapy, allowing to achieve a high cancer therapeutic efficiency. ${ }^{254}$

In conclusion, according to the relatively wide results available on biodegradability of $2 \mathrm{D}$ family materials beyond GFMs, we can conclude that there are two main biodegradation pathways: 1) a biochemical enzymatic process, and 2) a chemical redox process. Biochemical enzymatic process possesses greater advantage to degrade 2D family materials with high stability (e.g., $\mathrm{MoS}_{2}$ and hBN). Chemical redox reactions mediated by oxidants, such as $\mathrm{O}_{2}$ and $\mathrm{H}_{2} \mathrm{O}_{2}$, can degrade $2 \mathrm{D}$ family materials with low stability in intracellular and tissue environment (e.g., $\mathrm{MnO}_{2}$ and $\mathrm{BP}$ ). The assessment of biodegradability of $2 \mathrm{D}$ family materials not only ensure their biosecurity, but also promote their development for various applications.

\section{Degradation-by-design: effect of chemical functionalization on biodegradability of 2D materials}

In this section, we are mainly focusing our attention on how the chemical functionalization of 2D materials modulate their degradability. We will explain in depth the concept of "degradation-bydesign", to enhance the biodegradation of 2D materials, which involves the covalent functionalization with specific bioactive molecules able to increase the catalytic activity of peroxidases.

The recent reviews on biodegradation of $2 \mathrm{D}$ materials have evidenced that the characteristics of the original materials and their chemical modification influence their biological impact, eventually suggesting the development of safer nanomaterials by-design. ${ }^{108}$

Despite carbon nanotubes and graphene present very distinct features, their key physicochemical characteristics (i.e. structure, surface, chemical composition) can be compared to some extent. In this context, carbon nanotubes have offered a set of rules regarding biodegradation of graphene nanomaterials, ${ }^{126}$ due to the fact that they are "older" 255 and they have been extensively studied before GFMs started to be produced in high quantities. Different strategies have been investigated to improve the degradability of 2D nanomaterials. Some of them are atom doping, introduction of defective sites and oxygenated groups or even functionalization with specific ligands to make the nanomaterial more "attractive" as a substrate for certain enzymes. These strategies will be discussed in this section by illustrating related and remarkable literature examples.

The enzymatic degradation of multi-walled carbon nanotubes by $\mathrm{HRP} / \mathrm{H}_{2} \mathrm{O}_{2}$ was reported by Zhao et al. in $2011 .{ }^{136}$ The authors investigated the degradation of purified, nitrogen-doped and oxidized multi-walled carbon nanotubes. Different degrees of carboxylation were achieved by controlling the time of oxidative acid treatment. The authors found faster degradations of oxidized nanotubes compared to the pristine material thanks to the effective interaction between oxygencontaining defects on the nanotubes and the active site of the enzyme. Furthermore, it was demonstrated that the degradation took place layer-by-layer, on the defective sites of outer graphitic walls. In contrast to carboxylated nanotubes, the defective sites present in all graphitic walls of nitrogen-doped CNTs can trigger a complete degradation of the multi-walled carbon 
nanotubes by HRP.

The work on how to enhance the degradability of CNTs by appropriate chemical modifications, appeared in 2015, represents the first example of "degradation-by-design". 256 Two different azidocoumarin and one catechol derivatives were linked to multi-walled carbon nanotubes (Fig. 9). These molecules are good ligands for the peroxidases and act as reducing substrates and strong redox mediators to enhance the catalytic activity of the enzymes. In addition, xanthine oxidase was used to test the biodegradability of MWCNTs functionalized with an azidopurine. Both coumarin and catechol ligands were able to enhance the biodegradability rate of the nanotubes compared to the oxidized nanotube precursors. This is due to the capacity of these substrates to better interact with the active site of HRP. However, azidopurine-nanotubes were less degraded by xanthine oxidase than oxidized nanotubes, suggesting that the design in the case of this enzyme has to be reconsidered. This work illustrates the important role of the surface chemistry as a strategy to tune the enzymatic degradability of carbon nanotubes.

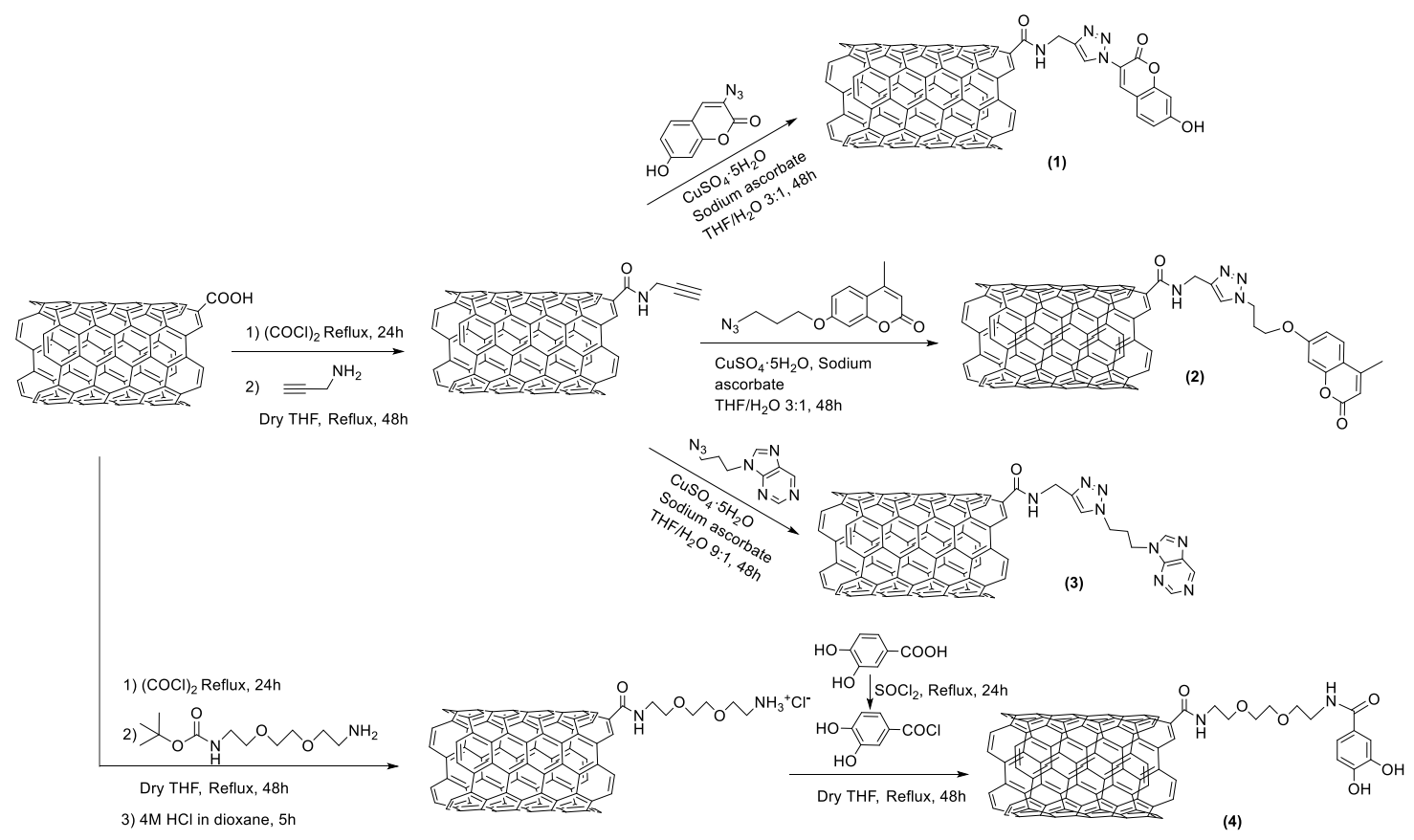

Fig. 9 Synthesis of the different functionalized multi-walled carbon nanotubes. Nanotube 1, 2 and 4 are modified with the coumarin and catechol substrates for HRP-mediated degradation. Nanotube 3 is functionalized with a purine substrate for degradation by xanthine oxidase. Reproduced with permission. ${ }^{256}$ Copyright 2015, Elsevier.

The role of functionalization on the biodegradation of carbon nanotubes was afterwards explored by Modugno et al. ${ }^{161}$ Double-walled and multi-walled carbon nanotubes of various lengths, degrees of oxidation and chemical functionalizations, using different methods, were treated with HRP. For this purpose, the introduction of amino groups both onto the sidewalls and at the tips of oxidized carbon nanotubes using amidation and 1,3-dipolar cycloaddition reactions was applied. While all tested double-walled nanotubes resulted resistant to degradation, short oxidized multi-walled carbon nanotubes functionalized by amidation were reduced in length and presented a high 
amount of defects after the treatment with the enzyme. This work showed the importance of the physicochemical characteristics of the nanotubes, including the structural defects and the dispersibility, concluding that a low dispersibility ends in a worse interaction between the nanomaterial and the enzyme, resulting therefore in a bad degradation capacity. Another example showed the in vivo biodegradability of multi-walled carbon nanotubes functionalized by Diels-Alder and further oxidized, in comparison to the pristine nanotubes. ${ }^{179}$

The examples and results obtained using CNTs have helped to understand a little more the nanomaterial-enzyme interactions and the degradation mechanisms, and the approach has been subsequently explored for other 2D materials. Kotchey et al. reviewed in 2012 the enzymecatalysed degradation of carbon nanomaterials, ${ }^{109}$ basically using hMPO or HRP. Most of the examples concerned carbon nanotubes, but the authors also analysed the role of functional groups in the degradation of reduced GO and GO. ${ }^{115}$ This work concluded that HRP catalyses the oxidation of $\mathrm{GO}$ but fails oxidizing reduced $\mathrm{GO}$, paving the way for future investigations on the role of functional groups present on the surface of graphene materials. Soon after, the surface coatingdependent degradation of graphene derivatives was reported. ${ }^{257} \mathrm{Li}$ et al. demonstrated that both PEGylation and conjugation with BSA (bovine serum albumin) protect the material from degradation by HRP. However, the authors solved the problem of degradability by conjugating PEG to GO via a cleavable disulphide bond, resulting in a hybrid that was partially degraded. In view of these data, the importance of the surface functional groups and the consequent enhancement of the dispersibility on biodegradability are clear. In fact, the dispersibility-dependent degradation of carbon nanomaterials was demonstrated for GO, ${ }^{110,112}$ and for single- and few-layer graphene. ${ }^{111}$ The works underline also how the level of oxidation of graphene directly correlates with the efficiency of degradation.

To enhance the rate of degradation of GFMs, the degradation-by-design strategy, applied to carbon nanotubes, was extended to GO. ${ }^{117}$ In this work GO was functionalized with coumarin and catechol to improve the interaction with HRP, as it had been previously demonstrated for carbon nanotubes, leading to a faster degradation of these functionalized materials (Fig. 10, part A) ${ }^{256} \mathrm{We}$ also found that amino functions on GO reduced the biodegradability compared to unmodified GO. To further expand the concept of degradation-by-design, our group reported in 2019 a study demonstrating an acceleration of the biodegradation of GO by hMPO after functionalization of the surface with the chemoattractant peptide $N$-formyl-methionyl-leucylphenylalanine (fMLP) (Fig. 10, part A). ${ }^{17}$ In addition, the fMLP-functionalized platform was loaded with doxorubicin. In this context, the drug was targeted to HeLa cells, which contain specific formyl peptide receptors, thanks to the presence of the fMLP ligand. The hybrid demonstrated a higher doxorubicin internalization and a higher cytotoxicity for cancer cells in vitro compared to the non-functionalized GO. In another recent article, Arnold et al. published the long-term biodegradation of graphene oxide with polyphosphate groups (Fig. 10, part B). ${ }^{258}$ Long-term safety has remained an issue due to the limitations of in vitro and in vivo models, which do not enough life span to predict a full lifetime of human use. The authors applied an ex vivo degradation method through which the degradation of the nanomaterial 
can be monitored indefinitely and sampled at any point during the degradation process, studying both the chemical structures and the physical properties of the aged materials. They found that phosphate-modified GO chemically degrade over time in aqueous and enzymatic conditions, eluting osteoinductive cations and anions. All these examples highlight that the biodegradation of graphene family materials is strongly dependent on the type of functional molecules attached to their surface.

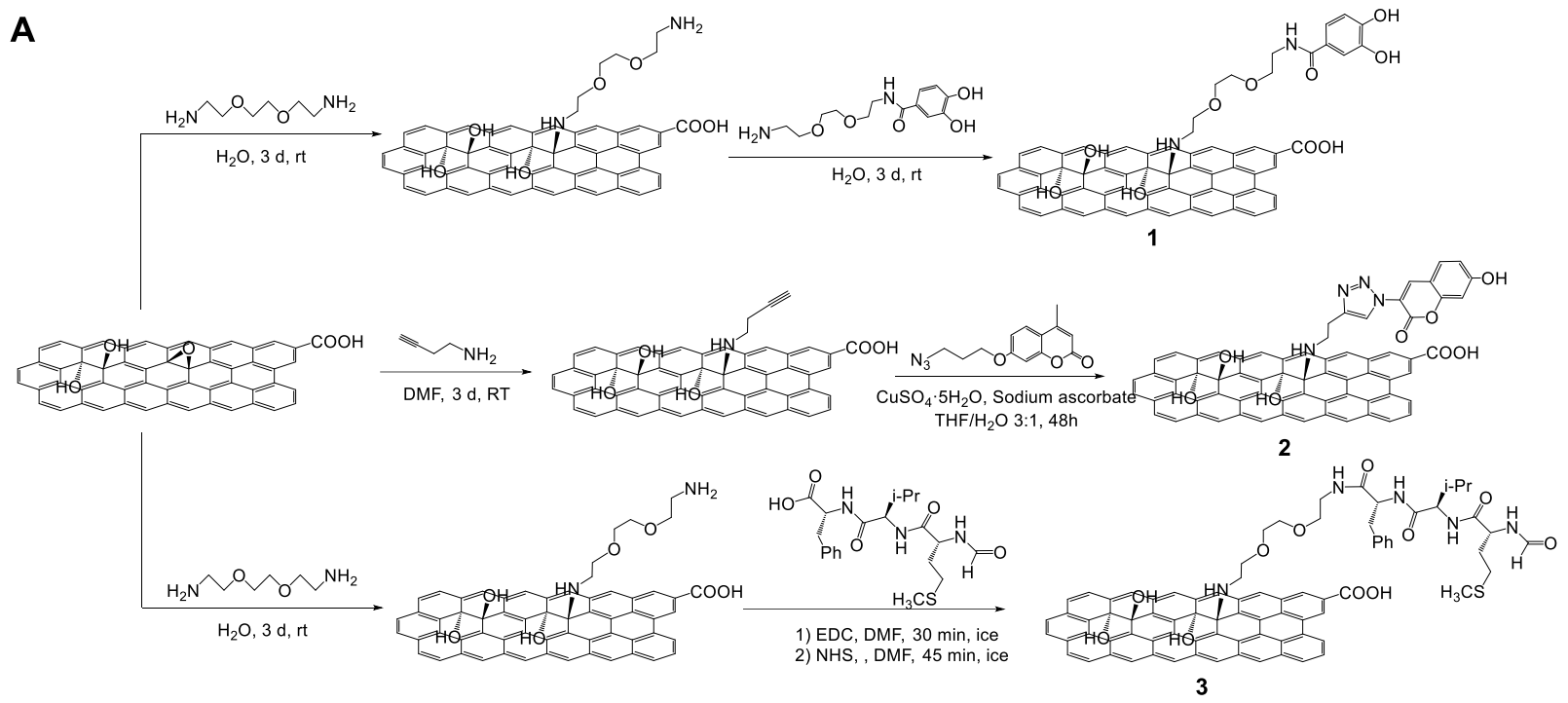

B

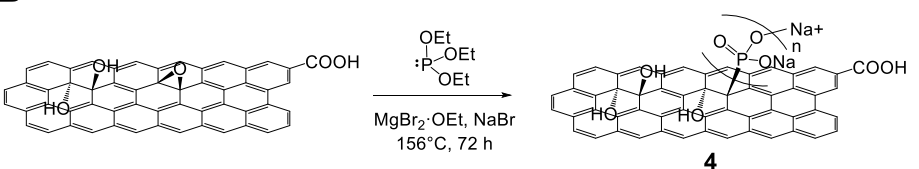

Fig. 10 (A) Synthesis of the different functionalized GO. GO 1 and 2 are modified with the catechol and coumarin substrates for HRP-mediated degradation. GO 3 is functionalized with the chemotactic peptide fMPL for hMPO-mediated degradation. (B) GO 4 is modified by polyphosphate chains.

Degradation-by-design has been recently extended also to the other 2D nanomaterials. In this context, the biodegradability of water dispersible pristine $\mathrm{MoS}_{2}$ and acetamide functionalized-MoS 2 nanosheets was examined. ${ }^{113}$ The results showed that the chemical modification of this TMD tunes the degradability and in particular it endows the material with a higher physiological stability. It has been demonstrated that pristine $\mathrm{MoS}_{2}$ is instable in the presence of $\mathrm{O}_{2}$, and degraded in various oxidizing aqueous conditions. ${ }^{259}$ In another work, in vivo degradation of different TMDs was evaluated. ${ }^{223}$ The authors demonstrated that PEGylated $\mathrm{MoS}_{2}$ can be degraded and excreted within one month, while the PEGylated $\mathrm{WS}_{2}$ and $\mathrm{TiS}_{2}$ nanosheets showed accumulation in reticuloendothelial systems (e.g., liver and spleen) after intravenous injection. This work clearly suggests the use of $\mathrm{MoS}_{2}$ as a particularly interesting material among other TMDs for biomedical applications, pointing out also the important role of the material itself, regardless of the functionalization strategy followed. Besides, in a different work, He and co-workers informed about 
a novel one-pot hydrothermal synthesis of degradable $\mathrm{MoS}_{2}$ using poly(acrylic acid) (PAA). They also demonstrated that the PEGylation of the PAA-MoS ${ }_{2}$ nanosheets via amide bond formation, leads to final $\mathrm{MoS}_{2}$ hybrids that are quickly degraded in $\mathrm{PBS}$ at $\mathrm{pH} 7.4$, showing excellent stability in several media and outstanding photothermal properties. ${ }^{222}$ It is therefore important to understand the crucial role played by the specific ligands anchored to the 2D materials on their stability in physiological conditions and consequently on their biodegradability.

The easy aggregation, fast degradation, and insufficient stability of Xenes limit their application in biological conditions. Compared to their pristine forms, surface functionalized 2D Xenes exhibit enhanced dispersion stability and surface reactivity. ${ }^{63}$ Therefore, it is very important to prepare Xenes modified with adjustable degradation rates for both the best therapeutic efficacy and the lowest systemic toxicity. The degradability of black phosphorus, for instance, was shown to be dependent on chemical functionalization. ${ }^{260}$ Exfoliated BP functionalized with aryl diazonium salts presents reduced degradation rate exposed to ambient conditions compared to pristine BP flakes. In a different work, Huang et al. described how the decoration of $\mathrm{BP}$ with $\mathrm{Bi}_{2} \mathrm{O}_{3}$ nanoparticles inhibits the rapid degradation of the nanosheets by occupation of the defect sites. ${ }^{261}$ This fact sends back to GFMs, in the sense that defects improve the biodegradation of the nanomaterials by enzymes. However, while defects are oxygenated functional groups enhancing biodegradation for GFMs, decorating $\mathrm{BP}$ with $\mathrm{Bi}_{2} \mathrm{O}_{3}$ nanoparticles reduces the degradation rate. Other protection strategies, such as atomic layer deposition of $\mathrm{AlO}_{x}$, have been used to prevent phosphorene from degradation. 202,262 In the case of other Xenes, the rapid degradation of bismuthene in air can be slowed down, for instance, by depositing a thin (1-5 nm), amorphous silicon capping layer under ultra-high vacuum. ${ }^{263}$ Other authors suggested that partial surface oxidation of bismuthene could also prevent further inner degradation, as it happens when superficial aluminum oxide protects deeper aluminum from oxidation. ${ }^{264}$ In the case of antimonene, Tao et al. developed a photonic drug-delivery platform based on 2D PEGylated antimonene nanosheets. ${ }^{66}$ The authors performed in vivo studies, and demonstrated the inhibition of tumor growth and the potential degradability of the hybrids with no side effects.

The surfaces of other Xenes such as borophene, ${ }^{265}$ silicene, ${ }^{266}$ or tellurene, ${ }^{69,267}$ have been already functionalized. However, degradation rates of these last mentioned modified 2D Xenes have not been tested yet. In summary, although Xenes resulted relatively safe in terms of cytotoxicity, their degradation is one of the main issues that needs to be systematically investigated before envisaging pervasive therapeutic applications of these $2 \mathrm{D}$ materials. In addition, the biodegradation studies of 2D Xenes by plant or human enzymes in still missing.

Regarding 2D Mxenes, the fabrication of devices and functional coatings, based for instance on $\mathrm{Ti}_{3} \mathrm{C}_{2} \mathrm{~T}_{x}$, remains challenging as they are prone to chemical degradation by their oxidation to $\mathrm{TiO}_{2}$. $\mathrm{Ti}_{3} \mathrm{C}_{2} \mathrm{~T}_{x}$ acceleration of its oxidation under UV light has been recently reported. ${ }^{268}$ Besides, Li et al. have reviewed the environmental stability of Mxenes:269 (i) at low temperatures, dark, vacuum and inert atmosphere are effective ways to isolate moisture and oxygen, and avoid the oxidation tendency; (ii) at high temperatures, the oxidation a occurs faster; and (iii) under hydrothermal 
conditions (e.g., high temperature and pressure), more varied microstructural transformations can be obtained. Therefore, tuning physically the degradation of $2 \mathrm{D}$ MXenes is possible, but the influence of chemical modifications needs to be further investigated. In addition, the biodegradation studies of those new modified 2D materials by plant or human-derived enzymes should be studied as well.

We would like to conclude highlighting that the degradation-by-design concept can also imply the possibility to devise new artificial enzymes mimicking natural peroxidases capable to degrade GFMs, and 2D materials under controlled conditions. We have already mentioned above DNAzymes composed of guanine rich G-quadruplexes capable to degrade GO similar to HRP. ${ }^{118}$ These peroxidase mimetics could be useful to understand the degradation reactions of $2 \mathrm{D}$ materials in long term studies, since they have the better stability at ambient temperature unlike natural enzymes.

In conclusion, based on the few existing literature reports, we can assume that the mechanisms of degradation of carbon-based nanomaterials is different from the degradation mechanisms followed by other 2D nanomaterials, certainly due to the different chemical compositions. It is also evident that functionalization has a different influence. While it helps to biodegrade faster carbonbased nanomaterials, it seems to disturb when degrading 2D materials. Despite the abovementioned investigations, a careful engineering research on 2D materials is still required from the point of view of the degradation. Surface functionalization strategies together with the use of relevant in vitro and in vivo models are necessary to better understand the possible risks of longterm biopersistence of such materials. With this in mind, one may anticipate novel applications by making these 2D nanomaterials safer-by-design.

\section{Biomedical applications of biodegradable products containing 2D materials}

One of the purposes of developing biodegradable materials is to utilize them directly or to produce corresponding functional products for further applications. The potential applications or the possible final products containing biodegradable 2D materials can stimulate further development, and can be also used as a standard to assess the value of $2 \mathrm{D}$ materials. ${ }^{180,270}$ Based on the different structures, properties and biodegradation behaviour, biodegradable 2D materials can present different promises in various fields of applications, including the biomedical. In this section, the applications of biodegradable 2D materials in cancer therapy, tissue engineering, and the possible final technological products (e.g., electronic skins and gas sensors) will be discussed in detail.

There are several applications of biodegradable 2D materials in cancer therapy. ${ }^{184,218,232,271,272}$ They are efficient carriers for drug delivery, and can be exploited for PTT, and can be used as specific agents for CDT. For drugs delivery and PTT, 2D materials should maintain their original structure during the time of action, and then be degraded gradually by enzymatic catalysis or redox reaction. ${ }^{200}$ PTT combined with drug delivery has also been widely explored to improve the therapeutic efficiency. ${ }^{271}$ In the case of CDT, biodegradable 2D materials can react with 
intracellular matters directly, leading to cancer cell ablation by causing intracellular homeostasis disequilibrium. ${ }^{232}$ After redox reactions, the structure and constituents of $2 \mathrm{D}$ materials change, meaning that they have been simultaneously degraded.

Due to the high specific surface area and relative safety, a certain number of biodegradable 2D materials have been used as drug transporters ${ }^{273}$ or photothermal conversion agents for cancer therapy. ${ }^{274}$ Typically, biodegradable GO and BP nanosheets have been widely studied. 17,189,275,276 Our group has designed a multifunctional GO nanoplatform with intrinsic biodegradability and targeting capacity. ${ }^{17} \mathrm{GO}$ functionalized with fMLP (GOfMLP) is able to deliver the chemotherapeutic DOX faster into cells, inducing higher levels of apoptosis, and is capable of inducing neutrophil degranulation with subsequent degradation (Fig. 11). The results demonstrate that this ad hoc modified GO is a promising carrier able to efficiently deliver anticancer drugs, being endowed with the ability to induce self-biodegradation. Alternatively, BP has been also used to deliver drugs or genes, and as agent for photothermal therapy. ${ }^{275,277,278}$ BP-agarose hydrogel can accurately release DOX intracellularly, triggered by near-infrared light (NIR). ${ }^{275}$ Under NIR irradiation, agarose hydrogel was degraded into segments, oligomers, and monomers and finally carbon dioxide and water by hydrolysis of the ester bonds, while BP was degraded into phosphate and phosphonate by $\mathrm{O}_{2}$ and $\mathrm{H}_{2} \mathrm{O}$. Besides, agarose hydrogel can also regulate the degradation rate of $\mathrm{BP}$ increasing its stability. Moreover, dopamine encapsulation can effectively prevent the rapid degradation of BP, maintaining a good stability for efficient PTT. ${ }^{277}$ Furthermore, $\mathrm{Mo}_{2} \mathrm{C}$-PVA nanoflakes were used for PTT due to the good biocompatibility, strong NIR absorbance, and high photothermal-conversion efficiency, and can be degraded into soluble $\mathrm{MoO}_{4}{ }^{2-}$ ions in the presence of the oxygen dissolved in water. ${ }^{214}$ Therefore, degradable 2D materials can be designed as functional nanoplates for cancer therapy by drug delivery and photothermal therapy.
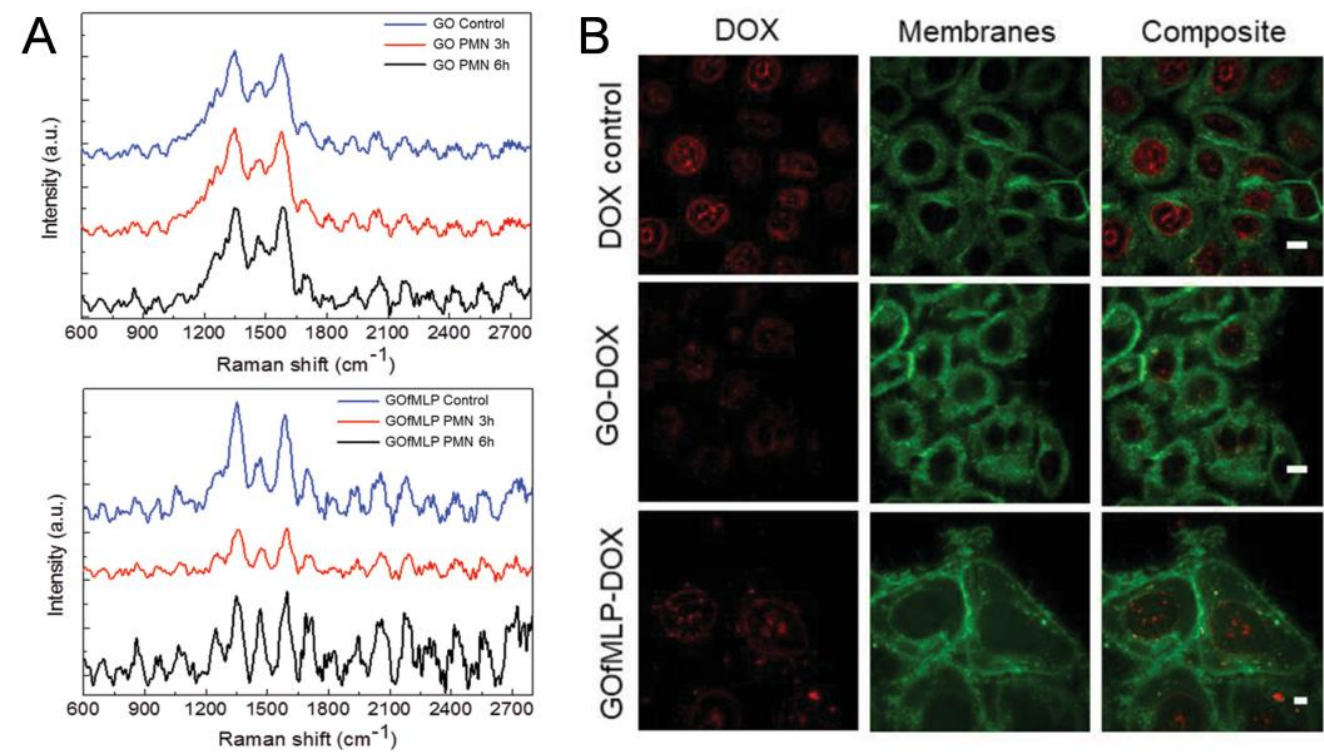

Fig. 11 GOfMLP as a biodegradable nanoplatfrom to delivery drug for cancer therapy. (A) Raman spectral changes of GOfMLP during hMPO catalytic biodegradation. (B) Delivery of DOX into cancer cells by GOfMLP. Reproduced with permission. ${ }^{17}$ Copyright 2019 , Wiley. 
Some $2 \mathrm{D}$ materials are sensitive to the tumour microenvironment (such as $\mathrm{pH}, \mathrm{H}_{2} \mathrm{O}_{2}$, and $\mathrm{GSH}$ ). After the reaction with the intracellular molecules and ions, these $2 \mathrm{D}$ materials cause cancer cell death by CDT and get degraded at the same time. These 2D materials usually belong to $\mathrm{TMO}$ family. For example, $\mathrm{MnO}_{2}$ nanosheets react with $\mathrm{GSH}$ generating $\mathrm{Mn}^{2+}$ ions and GSSG. Subsequently, $\mathrm{Mn}^{2+}$ ions convert $\mathrm{H}_{2} \mathrm{O}_{2}$ into $\mathrm{HO}$ in the presence of physiological $\mathrm{HCO}_{3}{ }^{-}$ions. $\mathrm{GSH}$ depletion and $\mathrm{HO}$ generation finally cause cancer cell death. ${ }^{232} \mathrm{Co}_{3} \mathrm{O}_{4}$ nanoprisms modified with BSA can degrade liberating $\mathrm{Co}^{3+}$ ions in the presence of $\mathrm{H}_{2} \mathrm{O}_{2}$ and $\mathrm{H}^{+}$ via a redox reaction. The generated $\mathrm{Co}^{3+}$ ions serve as a selective catalyst for $\mathrm{H}_{2} \mathrm{O}_{2}$ degradation leading to generation of hydroxyl radicals through the Fenton-like reaction, which increases intracellular oxidative stress and cause cell mortality. ${ }^{237}$ According to these results, it can conclude that the redox reactions between $2 \mathrm{D}$ materials with intracellular matters provide the basis for CDT, and also offer an alternative strategy to develop new biodegradable 2D materials that do not rely on enzymatic degradation.

Moreover, many 2D materials have been applied in tissue engineering. ${ }^{153,279,280}$ Because biodegradable 2D materials usually should be converted into a part of the human body after degradation, they are more suitable in the process of reparation injured tissues compared to biopersistent materials. It was found that a self-supporting graphene hydrogel film was able to stimulate osteogenic differentiation of stem cells in vitro and in vivo. ${ }^{281}$ After being subcutaneously implanted in rats, the film can promote bone tissue regeneration and blood vessel formation. Meanwhile, the film swelled and cracked in vivo, suggesting the beginning of degradation. A GO-copper (GO-Cu) nanocomposite-coated porous calcium phosphate scaffold was designed to promote vascularised bone regeneration by activating the Erk $1 / 2$ signalling pathway. ${ }^{282}$ Notably, in the defect regions, GO-Cu nanocomposites were both detected in the multinucleated giant cells, indicating that GO-Cu nanocomposites were phagocytosed and subsequently degraded.

It is well-known that the final degraded product of $\mathrm{BP}$ is $\mathrm{PO}_{4}{ }^{3-}$ ions, which can promote osteogenic differentiation and bone regeneration. A BP nanosheets-3D printed bioglass scaffold (BP-BG) was prepared for localised treatment of osteosarcoma and bone regeneration by stepwise therapeutic strategy (Fig. 12). ${ }^{283}$ In the initial phase, BP can kill cancer cells by photothermal effect. Then, the degraded product $\left(\mathrm{PO}_{4}{ }^{3-}\right)$ of $\mathrm{BP}$ can promote osteogenic differentiation of hBMSCs and osteogenesis in vivo. Furthermore, biodegradable BP and polyurethane (PU) composite (PU/BP) was designed as a new shape memory polymer with NIR-photoresponsive shape memory ability. ${ }^{284}$ After implanted into deep tissue, the PU/BP material enabled the rapid shape change under $808 \mathrm{~nm}$ light irradiation. Meanwhile, BP could be degraded into phosphate and it also accelerated the degradation of PU, whose degraded products are nontoxic carbon dioxide and water. Therefore, biodegradability of 2D materials not only ensure the biosecurity, but can be designed to promote tissue regeneration by exploiting the degraded products. 


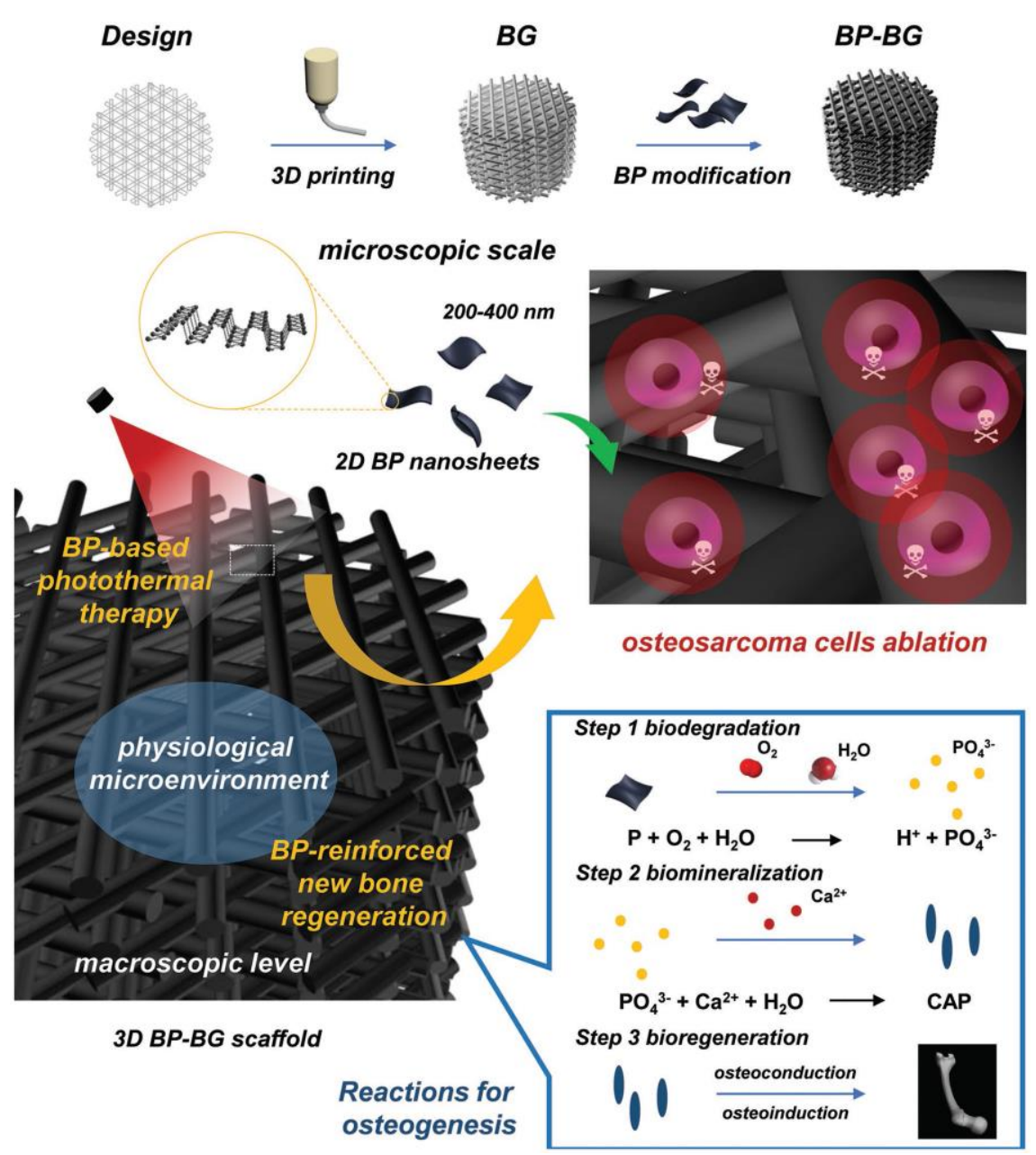

Fig. 12 Biodegradable 3D BP-BG scaffold for cancer therapy and bone regeneration by stepwise therapeutic strategy. First, BP-based PPT can be used to kill cancer cells efficiently. Then, the degraded product $\left(\mathrm{PO}_{4}{ }^{3-}\right.$ ions) of $\mathrm{BP}$ can promote bone repair. Reproduced with permission. ${ }^{283}$ Copyright 2018, Wiley.

In the field of bioelectronics, biodegradable 2D materials are promising because of the high safety and bioresorbable properties in vivo. Until now, graphene and $\mathrm{MoS}_{2}$ are the most used two 2D materials, which are maturely applied in bioresorbable electronics. Graphene has high electronic mobility, which is helpful for the applications in the corresponding electronic devices. ${ }^{285}$ Due to the biodegradability of both graphene and silk, a bioresorbable graphene/silk passive wireless telemetry system was developed to detect bacteria on tooth enamel. ${ }^{286}$ Alternatively, $\mathrm{MoS}_{2}$ has also shown several advantages, including 2D electron confinement, strong in-plane covalent bonding, flexibility and optical transparency. ${ }^{287-289}$ Those properties are significant for applications in transparent and bendable electronic devices. It has been demonstrated that $\mathrm{MoS}_{2}$ in electronic devices undergoes slow hydrolysis in PBS solution without adverse biological effects. ${ }^{221}$ The biodegradability of $\mathrm{MoS}_{2}$ usually begins at the defect rich areas, such as the grain boundaries and locations of point defects. Usually, over 2 months are needed to completely degrade and adsorb a polycrystalline $\mathrm{MoS}_{2}$ monolayer of $\sim 200 \mathrm{~nm}$ size in PBS solution at $37^{\circ} \mathrm{C}$. Moreover, it has been shown that temperature, $\mathrm{pH}$, and the type and 
concentration of ions could influence the degradation rate. ${ }^{221}$ Meanwhile, another kind of $\mathrm{MoS}_{2^{-}}$ based bioabsorbable and multifunctional sensor was fabricated for intracranial monitoring of pressure, temperature, strain, and motion in animal models according to the resistance changes. ${ }^{290}$ After 4 weeks, the implanted $\mathrm{MoS}_{2}$ film was gradually degraded and dissolved into the interstitial fluid of mice.

In conclusion, due to the good biocompatibility and biodegradability, innumerable 2D materials with different properties have been widely applied in varied fields, such as cancer therapy, tissue repair and bioresorbable electronic devices. The assessment of biodegradability ensures the biosecurity when 2D materials are used in vivo, which is very significant and helpful to further clinical applications, and also provides beneficial guidance to design and develop multifunctional 2D materials system for advanced applications.

Taking into consideration the biomedical applications described above, it is necessary for $2 \mathrm{D}$ materials to have also stability, against biodegradation by enzymatic catalysis or redox reaction, adapted to the specific applications. For example, for delivery of drugs and for photothermal therapy, 2D materials need to be stable (for few days) until the drugs are released at the specific site of action (e.g., cancer cells) and PTT is performed. As many 2D materials are used as scaffolds in tissue engineering, these materials should be stable for longer time periods (approximately a few weeks). ${ }^{283}$ In the case of bioelectronic devices used for brain interfacing, $\mathrm{MoS}_{2}$ sheets, for example, were stable up to 4 weeks. These examples highlight as the time frames for biodegradation are based on specific applications and the appropriate $2 \mathrm{D}$ material should be carefully selected before processing.

\section{Conclusion and Perspectives}

In summary, the discovery of graphene and other 2D materials is not only revolutionary for various industrial applications ranging from aerospace engineering to electronics, energy, and composites, but it also led to a remarkable research activity in developing various biomedical applications including bioelectronics. Although several promising biomedical uses of 2D materials (e.g., drug and gene delivery, bioimaging, theranostics, implants, etc.) have been already reported, the fate of these new materials in living organisms should be better understood, expanding the studies to their biodegradability in physiological conditions. In general, the nanomaterials are administered intravenously or orally for delivery of drugs to the target organs, or in some cases materials could be implanted in the organs for sensing, imaging (diagnosis), and tissue regeneration. Therefore, assessing the biodegradability of $2 \mathrm{D}$ materials is mandatory for a safe translation into clinics. Most of the biodegradation studies of $2 \mathrm{D}$ materials were performed using peroxidases secreted by immune cells like neutrophils, macrophages, eosinophils, or treating the materials in gastric juices, or physiological pH. ${ }^{109,128,132,144,156,291-294}$ However, the current degradation studies are limited as relevant models either using in vitro cells (in time frame of days to weeks) or animal models (in a timeframe of months) are lacking. ${ }^{258}$ 
It is clear that the degradation of $2 \mathrm{D}$ materials depends on the type of material. Inorganic materials (e.g., $\mathrm{BP}, \mathrm{MoS}_{2}$, etc.) are more easily degradable compared to organic 2D materials like graphene. Moreover, aqueous dispersibility of the $2 \mathrm{D}$ materials is also an important parameter to evaluate, because highly dispersible GO samples were proven to be highly degradable over poorly dispersible GO. In addition, redox potentials of specific peroxidases can clearly influence the degradation process in vivo. For example, MPO has redox potential $\left(\mathrm{E}^{\circ} \sim 1.16 \mathrm{eV}\right)$, which explains a better biodegradability of GO compared to EPO ( $\left.E^{\circ} \sim 1.10 \mathrm{eV}\right)$, and $\mathrm{HRP}\left(\mathrm{E}^{\circ} \sim 1.0 \mathrm{eV}\right)$.

Importantly, it has been demonstrated that the chemical modifications and covalent functionalization (e.g., oxidation or functionalization with ligands) play a key role in tuning the degradability of carbon-based nanomaterials. Especially, oxidized graphitic materials (e.g. GO and CNTs) were found to be easily degraded by the peroxidases compared to the pristine materials. Indeed, the oxidation of GFMs initiates at the defects and at the level of C-O bonds. ${ }^{115}$ To enhance and control the biodegradability of any materials, the "degradation-by-design" concept holds a lot of potential. The possibility to covalently functionalize 2D materials with bioactive molecules (like the substrates of HRP) ${ }^{117,256}$ or chemoattractant peptides (to increase for example the oxidative activity of hMPO) is of high interest to design safer biomedical tools. ${ }^{17}$ However, this concept has been developed very little and mainly applied to GFMs. It is clear that this concept can be easily extended to non-metallic $2 \mathrm{D}$ materials like $\mathrm{h}-\mathrm{BN}$ and $\mathrm{g}-\mathrm{C}_{3} \mathrm{~N}_{4}$, by designing covalent modifications to accelerate the degradation compared to non-functionalized materials. In contrast, the covalent functionalization of $\mathrm{MoS}_{2}$ or BP should be aimed to reduce the speed of their biodegradation. ${ }^{113,260}$ On the other hand, since $\mathrm{MoS}_{2}$, phosphorene, MXenes, etc. are generally devoid of reactive organic functional units on their surface, a controlled covalent chemical modification with bioactive molecules or ligands is more challenging, but not impossible. ${ }^{187}$ We believe that the application of "degradation-by-design" to inorganic 2D materials is one of the ways to render them safer in different domains of applications. In addition, the development of new surface functionalization strategies together with the use of relevant in vitro and in vivo models are necessary to better understand the possible risks of long-term biopersistence of such materials.

Based on the available reports, hBN is the most difficult $2 \mathrm{D}$ material to be degraded by peroxidases followed by the graphene, ${ }^{111,114}$ graphene oxide, ${ }^{112}$ and transition metal dichalcogenides ${ }^{113}$ Black phosphorus is the fastest degradable materials, since it can be easily degraded by moisture and oxygen. ${ }^{194,195,262,295,296}$ It is clear that the degradation of GFMs is different from other inorganic 2D nanomaterials, mainly due to the difference in the chemical composition and chemical bonding. Though the major end products resulting from the biodegradation of graphene materials are $\mathrm{CO}$ and $\mathrm{CO}_{2}$ along with many polyaromatic hydrocarbons, the long-term effects of these by-products are still unclear. ${ }^{109}$ Similarly, the end products of other 2D materials (except phosphorene) must be clearly understood to better conceive safer in vivo biomedical applications. By comparing all 2D materials, their degradability and cytocompatibility, BP seems to be very promising for biomedical applications due to their ultrahigh surface area, ease of fabrication, high photothermal conversion ability, excellent biocompatibility and faster degradability, 
leading to formation of phosphate ions, one of the main components of the bones. ${ }^{297}$ As the pristine $\mathrm{BP}$ is degradable within hours in water and atmospheric oxygen, various chemical functionalization methods have been already developed to introduce P-C or P-O-C bonds to reduce its rapid degradation. ${ }^{298}$ With all these examples in mind, one may preview novel chemical strategies to make 2D nanomaterials degradable-by-design.

In conclusion, this review is aimed to highlight the key importance of biodegradability of 2D materials, and in particular the role of chemical functionalization that is fundamental to modulate their degradation mechanisms. Chemical functionalization of $2 \mathrm{D}$ materials is reasoned to be critically important for example in determining the rate of the catalytic reactions occurring during the enzymatic degradation. Therefore, functionalized 2D materials can be rationally designed by exploiting versatile chemical approaches. Suitable functional groups able to attract degradative enzymes can be covalently linked to $2 \mathrm{D}$ materials. 2D Materials can be modified by functionalization with substrates that prevent enzyme inactivation or with substrates that enhance enzyme activity, or with molecules with pro-oxidant effects (e.g., generation of $\mathrm{H}_{2} \mathrm{O}_{2}$ ), or with ligands (e.g., aptamers) that preferentially bind to specific enzymes.

In the development of various biomedical products and for a real translation of the laboratory research into clinical setting, the assessment and control of the biodegradability is one of the crucial parameters. Though the number of 2D materials are increasingly reported, their degradability in the physiological conditions is poorly studied. The lessons learnt from the graphene family materials and few 2D materials should guide future biodegradation studies and help the researchers for a better design not only of biomedical products and tools, but also in the field of materials science, to avoid the potential problems associated to environmental disposal.

\section{Acknowledgements}

The authors gratefully acknowledge the financial support from the EU Graphene Flagship project (no. 785219). This work was partly supported the Agence Nationale de la Recherche (ANR) through the LabEx project Chemistry of Complex Systems (ANR-10-LABX-0026_CSC). We wish to acknowledge the Centre National de la Recherche Scientifique (CNRS) and the International Center for Frontier Research in Chemistry (icFRC). RK wants to thank the financial support from the Science Foundation Ireland (SFI) and the European Regional Development Fund under Grant Number 13/RC/2073.

\section{References}

1 G. Gao, W. Gao, E. Cannuccia, J. Taha-Tijerina, L. Balicas, A. Mathkar, T. Narayanan, Z. Liu, B. K. Gupta and J. Peng, Nano Lett., 2012, 12, 3518-3525.

2 A. K. Geim, science, Science, 2009, 324, 1530-1534.

3 K. S. Novoselov, V. Fal, L. Colombo, P. Gellert, M. Schwab and K. Kim, Nature, 2012, 490, 192-200.

4 P. Wick, A. E. Louw - Gaume, M. Kucki, H. F. Krug, K. Kostarelos, B. Fadeel, K. A. Dawson, A. Salvati,

E. Vázquez and L. Ballerini, Angew. Chem. Int. Ed., 2014, 53, 7714-7718.

5 C. Backes, A. M. Abdelkader, C. Alonso, A. Andrieux-Ledier, R. Arenal, J. Azpeitia, N. Balakrishnan, L. Banszerus, J. Barjon and R. Bartali, 2D Mater., 2020, 7, 022001.

6 A. T. Smith, A. M. LaChance, S. Zeng, B. Liu and L. Sun, Nano Mater. Sci., 2019, 1, 31-47. 
7 L. Zhou, L. Fox, M. Włodek, L. Islas, A. Slastanova, E. Robles, O. Bikondoa, R. Harniman, N. Fox and M. Cattelan, Carbon, 2018, 136, 255-261.

8 J. M. González-Domínguez, V. León, M. I. Lucío, M. Prato and E. Vázquez, Nat. Protoc., 2018, 13, 495.

9 A. Celis, M. Nair, A. Taleb-Ibrahimi, E. Conrad, C. Berger, W. De Heer and A. Tejeda, J. Phys. D Appl. Phys., 2016, 49, 143001.

10 Y. Zhu, H. Ji, H.-M. Cheng and R. S. Ruoff, Nat. Sci. Rev., 2018, 5, 90-101.

11 G. Reina, J. M. Gonzalez-Dominguez, A. Criado, E. Vazquez, A. Bianco and M. Prato, Chem. Soc. Rev., 2017, 46, 4400-4416.

12 F.-Y. Su, C. You, Y.-B. He, W. Lv, W. Cui, F. Jin, B. Li, Q.-H. Yang and F. Kang, J. Mater. Chem., 2010, 20, 9644-9650.

13 S. Teng, Y. Gao, F. Cao, D. Kong, X. Zheng, X. Ma and L. Zhi, Prog. Org. Coat., 2018, 123, 185-189. 14 P. Xu, J. Kang, J.-B. Choi, J. Suhr, J. Yu, F. Li, J.-H. Byun, B.-S. Kim and T.-W. Chou, ACS Nano, 2014, 8, 9437-9445.

15 D. Nikolaev, V. Popov, A. Trofimova, N. Sleptsov, V. Timofeev and S. Smagulova, AIP Conf. Proc., AIP Publishing LLC, 2018, 2041, 020014.

16 C. Cheng, S. Li, A. Thomas, N. A. Kotov and R. Haag, Chem. Rev., 2017, 117, 1826-1914.

17 C. Martín, A. Ruiz, S. Keshavan, G. Reina, D. Murera, Y. Nishina, B. Fadeel and A. Bianco, Adv. Funct. Mater., 2019, 29, 1901761.

18 A. Servant, A. Bianco, M. Prato and K. Kostarelos, Bioorg. Med. Chem. Lett., 2014, 24, 1638-1649.

19 J. Ping, Y. Zhou, Y. Wu, V. Papper, S. Boujday, R. S. Marks and T. W. Steele, Biosens. Bioelectron., 2015, 64, 373-385.

20 J. N. Tiwari, V. Vij, K. C. Kemp and K. S. Kim, ACS Nano, 2016, 10, 46-80.

21 C. Martín, S. Merino, J. M. González-Domínguez, R. Rauti, L. Ballerini, M. Prato and E. Vázquez, Sci. Rep., 2017, 7, 1-12.

22 A. Servant, V. Leon, D. Jasim, L. Methven, P. Limousin, E. V. Fernandez - Pacheco, M. Prato and K. Kostarelos, Adv. Healthc. Mater., 2014, 3, 1334-1343.

23 N. Shadjou and M. Hasanzadeh, J. Biomed. Mater. Res. A, 2016, 104, 1250-1275.

24 Y.-W. Chen, Y.-L. Su, S.-H. Hu and S.-Y. Chen, Adv. Drug Deliver. Rev., 2016, 105, 190-204.

25 K. Khan, A. K. Tareen, M. Aslam, R. Wang, Y. Zhang, A. Mahmood, Z. Ouyang, H. Zhang and Z. Guo, J. Mater. Chem. C, 2020, 8, 387-440.

26 R. Scott, A. W. Achtstein, A. Prudnikau, A. Antanovich, S. Christodoulou, I. Moreels, M. Artemyev and U. Woggon, Nano Lett., 2015, 15, 4985-4992.

27 L. Yan, S. Gonca, G. Zhu, W. Zhang and X. Chen, J. Mater. Chem. B, 2019, 7, 5583-5601.

28 S. Banerjee, C. T. Lollar, Z. Xiao, Y. Fang and H.-C. Zhou, Trends Chem., 2020, 2, 467-479.

29 H.-C. Zhou, J. R. Long and O. M. Yaghi, Chem. Rev., 2012, 112, 673-674.

30 S. Bhunia, K. A. Deo and A. K. Gaharwar, Adv. Funct. Mater., 2020, 2002046.

31 S. Manzeli, D. Ovchinnikov, D. Pasquier, O. V. Yazyev and A. Kis, Nat. Rev. Mater., 2017, 2, 17033. 32 W. Choi, N. Choudhary, G. H. Han, J. Park, D. Akinwande and Y. H. Lee, Mater. Today, 2017, 20, 116-130.

33 A. Pospischil and T. Mueller, Appl. Sci., 2016, 6, 78.

34 M. R. Vazirisereshk, A. Martini, D. A. Strubbe and M. Z. Baykara, Lubricants, 2019, 7, 57.

35 Z. Li, X. Meng and Z. Zhang, J. Photoch. Photobio. C Photochem. Rev., 2018, 35, 39-55.

36 Z. Li and S. L. Wong, Mater. Sci. Eng. C, 2017, 70, 1095-1106.

37 T. Liu, C. Wang, X. Gu, H. Gong, L. Cheng, X. Shi, L. Feng, B. Sun and Z. Liu, Adv. Mater., 2014, 26, 3433-3440.

38 A. Sinha, B. Tan, Y. Huang, H. Zhao, X. Dang, J. Chen and R. Jain, TrAC Trend. Anal. Chem., 2018, 102, 75-90.

39 W. Z. Teo, E. L. K. Chng, Z. Sofer and M. Pumera, Chem. Eur. J., 2014, 20, 9627-9632.

40 Z. Zheng, M. Cox and B. Li, J. Mater. Sci., 2018, 53, 66-99.

41 Q. Weng, X. Wang, X. Wang, Y. Bando and D. Golberg, Chem. Soc. Rev., 2016, 45, 3989-4012.

42 M. Yankowitz, Q. Ma, P. Jarillo-Herrero and B. J. LeRoy, Nat. Rev. Phys., 2019, 1, 112-125.

43 K. Zhang, Y. Feng, F. Wang, Z. Yang and J. Wang, J. Mater. Chem. C, 2017, 5, 11992-12022.

44 Z. Liu, Y. Gong, W. Zhou, L. Ma, J. Yu, J. C. Idrobo, J. Jung, A. H. MacDonald, R. Vajtai and J. Lou, Nat. Commun., 2013, 4, 1-8.

45 J. D. Caldwell, I. Aharonovich, G. Cassabois, J. H. Edgar, B. Gil and D. Basov, Nat. Rev. Mater., 2019, 4, 552-567.

46 G. Ciofani, S. Danti, G. G. Genchi, B. Mazzolai and V. Mattoli, Small, 2013, 9, 1672-1685.

47 A. Pakdel, Y. Bando and D. Golberg, ACS Nano, 2014, 8, 10631-10639.

48 W. Lei, V. N. Mochalin, D. Liu, S. Qin, Y. Gogotsi and Y. Chen, Nat. Commun., 2015, 6, 1-8.

49 Y. Zhang, S. F. Ali, E. Dervishi, Y. Xu, Z. Li, D. Casciano and A. S. Biris, ACS Nano, 2010, 4, 31813186.

50 Q. Weng, B. Wang, X. Wang, N. Hanagata, X. Li, D. Liu, X. Wang, X. Jiang, Y. Bando and D. Golberg, ACS Nano, 2014, 8, 6123-6130. 
51 H. Oughaddou, H. Enriquez, M. R. Tchalala, H. Yildirim, A. J. Mayne, A. Bendounan, G. Dujardin, M. A. Ali and A. Kara, Prog. Surf. Sci., 2015, 90, 46-83.

52 A. Dimoulas, Microelectron. Eng., 2015, 131, 68-78.

53 P. Vogt, Beilstein J. Nanotechnol., 2018, 9, 2665-2667.

54 L. Kou, C. Chen and S. C. Smith, J. Phys. Chem. Lett., 2015, 6, 2794-2805.

55 Z.-G. Shao, X.-S. Ye, L. Yang and C.-L. Wang, J. Appl. Phys., 2013, 114, 093712.

56 N. Gao, W. T. Zheng and Q. Jiang, Phys. Chem. Chem. Phys., 2012, 14, $257-261$.

57 X. Han, C. Liu, J. Sun, A. D. Sendek and W. Yang, RSC Adv., 2018, 8, 7196-7204.

58 X. Ling, H. Wang, S. Huang, F. Xia and M. S. Dresselhaus, Proc. Natl. Acad. Sci. U.S.A, 2015, 112, 4523-4530.

59 H. Liu, Y. Du, Y. Deng and D. Y. Peide, Chem. Soc. Rev., 2015, 44, 2732-2743.

60 A. Carvalho, M. Wang, X. Zhu, A. S. Rodin, H. Su and A. H. C. Neto, Nat. Rev. Mater., 2016, 1, 1-16.

61 J. C. Garcia, D. B. De Lima, L. V. Assali and J. F. Justo, J. Phys. Chem. C, 2011, 115, 13242-13246.

62 J. Dai and X. C. Zeng, RSC Adv., 2014, 4, 48017-48021.

63 W. Tao, N. Kong, X. Ji, Y. Zhang, A. Sharma, J. Ouyang, B. Qi, J. Wang, N. Xie, C. Kang, H. Zhang, O. C. Farokhzad and J. S. Kim, Chem. Soc. Rev., 2019, 48, 2891-2912.

64 S. Kaneko, H. Tsuchiya, Y. Kamakura, N. Mori and M. Ogawa, Appl. Phys. Express, 2014, 7, 035102. 65 R. G. Amorim and R. H. Scheicher, Nanotechnology, 2015, 26, 154002.

66 W. Tao, X. Ji, X. Zhu, L. Li, J. Wang, Y. Zhang, P. E. Saw, W. Li, N. Kong, M. A. Islam, T. Gan, X. Zeng, H. Zhang, M. Mahmoudi, G. J. Tearney and O. C. Farokhzad, Adv. Mater., 2018, 30, 1802061.

67 X. Ji, N. Kong, J. Wang, W. Li, Y. Xiao, S. T. Gan, Y. Zhang, Y. Li, X. Song, Q. Xiong, S. Shi, Z. Li, W. Tao, H. Zhang, L. Mei and J. Shi, Adv. Mater., 2018, 30, 1803031.

68 W. Tao, X. Zhu, X. Yu, X. Zeng, Q. Xiao, X. Zhang, X. Ji, X. Wang, J. Shi and H. Zhang, Adv. Mater., 2017, 29, 1603276.

69 Y. Lin, Y. Wu, R. Wang, G. Tao, P. F. Luo, X. Lin, G. Huang, J. Li and H. H. Yang, Chem. Commun., 2018, 54, 8579-8582.

70 J. Ouyang, R.-Y. Liu, W. Chen, Z. Liu, Q. Xu, K. Zeng, L. Deng, L. Shen and Y.-N. Liu, J. Mater. Chem. B, 2018, 6, 6302-6310.

71 W. Chen, J. Ouyang, X. Yi, Y. Xu, C. Niu, W. Zhang, L. Wang, J. Sheng, L. Deng and Y. N. Liu, Adv. Mater., 2018, 30, 1703458.

72 J. Zhu, E. Ha, G. Zhao, Y. Zhou, D. Huang, G. Yue, L. Hu, N. Sun, Y. Wang and L. Y. S. Lee, Coordin. Chem. Rev., 2017, 352, 306-327.

73 M. Malaki, A. Maleki and R. S. Varma, J. Mater. Chem. A, 2019, 7, 10843-10857.

74 M. Naguib, O. Mashtalir, J. Carle, V. Presser, J. Lu, L. Hultman, Y. Gogotsi and M. W. Barsoum, ACS Nano, 2012, 6, 1322-1331.

75 M. A. Hope, A. C. Forse, K. J. Griffith, M. R. Lukatskaya, M. Ghidiu, Y. Gogotsi and C. P. Grey, Phys. Chem. Chem. Phys., 2016, 18, 5099-5102.

76 B. Xu, M. Zhu, W. Zhang, X. Zhen, Z. Pei, Q. Xue, C. Zhi and P. Shi, Adv. Mater., 2016, 28, 33333339.

77 C. N. R. Rao, Annu. Rev. Phys. Chem., 1989, 40, 291-326.

78 C. Yuan, H. B. Wu, Y. Xie and X. W. Lou, Angew. Chem. Int. Ed., 2014, 53, 1488-1504.

79 J. Meyer, S. Hamwi, M. Kröger, W. Kowalsky, T. Riedl and A. Kahn, Adv. Mater., 2012, 24, 54085427.

80 T. Yang, T. T. Song, M. Callsen, J. Zhou, J. W. Chai, Y. P. Feng, S. J. Wang and M. Yang, Adv. Mater. Interfaces, 2019, 6, 1801160.

81 G. Yang, L. Xu, Y. Chao, J. Xu, X. Sun, Y. Wu, R. Peng and Z. Liu, Nat. Commun., 2017, 8, 1-13.

82 D. Zeng, L. Wang, L. Tian, S. Zhao, X. Zhang and H. Li, Drug Deliv., 2019, 26, 661-672.

83 G. Song, J. Hao, C. Liang, T. Liu, M. Gao, L. Cheng, J. Hu and Z. Liu, Angew. Chem. Int. Ed., 2016, $55,2122-2126$.

84 X. Hu, F. Li, F. Xia, X. Guo, N. Wang, L. Liang, B. Yang, K. Fan, X. Yan and D. Ling, J. Am. Chem. Soc., 2020, 142, 1636-1644.

85 Z. Cao, B. Li, L. Sun, L. Li, Z. P. Xu and Z. Gu, Small Methods, 2020, 4, 1900343.

86 B. Li, Z. Gu, N. Kurniawan, W. Chen and Z. P. Xu, Adv. Mater., 2017, 29, 1700373.

87 S. Wang, X. Yang, L. Zhou, J. Li and H. Chen, J. Mater. Chem. B, 2020, 8, 2974-2989.

88 F. Zhao, H. Liu, S. D. Mathe, A. Dong and J. Zhang, Nanomaterials, 2018, 8, 15.

89 N. Mao, C. H. Zhou, D. S. Tong, W. H. Yu and C. C. Lin, Appl. Clay Sci., 2017, 144, 60-78.

90 Q. Wang and D. O'Hare, Chem. Rev., 2012, 112, 4124-4155.

91 J. Yu, Q. Wang, D. O'Hare and L. Sun, Chem. Soc. Rev., 2017, 46, 5950-5974.

92 J. Qu, L. Sha, C. Wu and Q. Zhang, Nanomaterials, 2019, 9, 80.

93 H. Pan, W. Wang, Q. Shen, Y. Pan, L. Song, Y. Hu and Y. Lu, RSC Adv., 2016, 6, 111950-111958.

94 J. Liu, L. Chen, H. Cui, J. Zhang, L. Zhang and C.-Y. Su, Chem. Soc. Rev., 2014, 43, 6011-6061.

95 M. Safaei, M. M. Foroughi, N. Ebrahimpoor, S. Jahani, A. Omidi and M. Khatami, TrAC Trends Anal. Chem., 2019, 118, 401-425.

96 G. Lan, K. Ni, R. Xu, K. Lu, Z. Lin, C. Chan and W. Lin, Angew. Chem. Int. Ed., 2017, 129, 12270- 
12274.

97 S. Wang, Q. Wang, P. Shao, Y. Han, X. Gao, L. Ma, S. Yuan, X. Ma, J. Zhou and X. Feng, J. Am. Chem. Soc., 2017, 139, 4258-4261.

98 R.-R. Liang, S.-Y. Jiang, A. Ru-Han and X. Zhao, Chem. Soc. Rev., 2020, 49, 3920-3951.

99 G. Das, F. Benyettou, S. K. Sharama, T. Prakasam, F. Gándara, A. Victor, N. i. Saleh, R. Pasricha, R. Jagannathan and M. A. Olson, Chem. Sci., 2018, 9, 8382-8387.

100 X. Zhan, Z. Chen and Q. Zhang, J. Mater. Chem. A, 2017, 5, 14463-14479.

101 R. W. Tilford, S. J. Mugavero III, P. J. Pellechia and J. J. Lavigne, Adv. Mater., 2008, 20, $2741-2746$.

102 J. Hu, J. Zhao and T. Yan, J. Phys. Chem. C, 2015, 119, 2010-2014.

103 D. Chimene, D. L. Alge and A. K. Gaharwar, Adv. Mater., 2015, 27, 7261-7284.

104 F. Yin, B. Gu, Y. Lin, N. Panwar, S. C. Tjin, J. Qu, S. P. Lau and K.-T. Yong, Coordin. Chem. Rev., 2017, 347, 77-97.

105 Z. Wang, W. Zhu, Y. Qiu, X. Yi, A. von dem Bussche, A. Kane, H. Gao, K. Koski and R. Hurt, Chem. Soc. Rev., 2016, 45, 1750-1780.

106 Y. Chen, C. Tan, H. Zhang and L. Wang, Chem. Soc. Rev., 2015, 44, 2681-2701.

107 V. E. Kagan, N. V. Konduru, W. Feng, B. L. Allen, J. Conroy, Y. Volkov, I. I. Vlasova, N. A. Belikova, N. Yanamala and A. Kapralov, Nat. Nanotechnol., 2010, 5, 354-359.

108 C. Martin, K. Kostarelos, M. Prato and A. Bianco, Chem. Commun., 2019, 55, 5540-5546.

109 G. P. Kotchey, S. A. Hasan, A. A. Kapralov, S. H. Ha, K. Kim, A. A. Shvedova, V. E. Kagan and A. Star, Acc. Chem. Res., 2012, 45, 1770-1781.

110 R. Kurapati, C. Martin, V. Palermo, Y. Nishina and A. Bianco, Faraday Discuss., 2020, 10.1039/C9FD00094A.

111 R. Kurapati, S. P. Mukherjee, C. Martín, G. Bepete, E. Vázquez, A. Pénicaud, B. Fadeel and A. Bianco, Angew. Chem. Int. Ed., 2018, 57, 11722-11727.

112 R. Kurapati, J. Russier, M. A. Squillaci, E. Treossi, C. Ménard - Moyon, A. E. Del Rio - Castillo, E. Vazquez, P. Samorì, V. Palermo and A. Bianco, Small, 2015, 11, 3985-3994.

113 R. Kurapati, L. Muzi, A. P. R. de Garibay, J. Russier, D. Voiry, I. A. Vacchi, M. Chhowalla and A. Bianco, Adv. Funct. Mater., 2017, 27, 1605176.

114 R. Kurapati, C. Backes, C. Menard-Moyon, J. N. Coleman and A. Bianco, Angew. Chem. Int. Ed., 2016, 55, 5506-5511.

115 G. P. Kotchey, B. L. Allen, H. Vedala, N. Yanamala, A. A. Kapralov, Y. Y. Tyurina, J. KleinSeetharaman, V. E. Kagan and A. Star, ACS Nano, 2011, 5, 2098-2108.

116 G. Lalwani, W. Xing and B. Sitharaman, J. Mater. Chem. B, 2014, 2, 6354-6362.

117 R. Kurapati, F. Bonachera, J. Russier, A. R. Sureshbabu, C. Ménard-Moyon, K. Kostarelos and A. Bianco, 2D Mater., 2018, 5, 015020.

118 R. Kurapati and A. Bianco, Nanoscale, 2018, 10, 19316-19321.

119 Y. Wei, F. Zhou, D. Zhang, Q. Chen and D. Xing, Nanoscale, 2016, 8, 3530-3538.

120 H. Y. Kim, F. Li, J. Y. Park, D. Kim, J. H. Park, H. S. Han, J. W. Byun, Y.-S. Lee, J. M. Jeong and K. Char, Biomaterials, 2017, 121, 144-154.

121 S. R. Shin, C. Zihlmann, M. Akbari, P. Assawes, L. Cheung, K. Zhang, V. Manoharan, Y. S. Zhang, M. Yüksekkaya and K. t. Wan, Small, 2016, 12, 3677-3689.

122 E. Morales - Narváez and A. Merkoçi, Adv. Mater., 2019, 31, 1805043.

123 L.-H. Pan, S.-H. Kuo, T.-Y. Lin, C.-W. Lin, P.-Y. Fang and H.-W. Yang, Biosens. Bioelectron., 2017, 89, 598-605.

124 J. Lin, Y. Huang and P. Huang, Biomedical Applications of Functionalized Nanomaterials, Elsevier, 2018, pp. 247-287.

125 G. Lalwani, M. D'Agati, A. M. Khan and B. Sitharaman, Adv. Drug Deliver. Rev., 2016, 105, 109144.

126 C. Bussy, H. Ali-Boucetta and K. Kostarelos, Acc. Chem. Res., 2013, 46, 692-701.

127 A. C. Jachak, M. Creighton, Y. Qiu, A. B. Kane and R. H. Hurt, MRS Bull., 2012, 37, 1307-1313.

128 M. Chen, X. Qin and G. Zeng, Trends Biotechnol., 2017, 35, 836-846.

129 I. I. Vlasova, A. A. Kapralov, Z. P. Michael, S. C. Burkert, M. R. Shurin, A. Star, A. A. Shvedova and V. E. Kagan, Toxicol. Appl. Pharm., 2016, 299, 58-69.

130 X. Zhou, Y. Zhang, C. Wang, X. Wu, Y. Yang, B. Zheng, H. Wu, S. Guo and J. Zhang, ACS Nano, 2012, 6, 6592-6599.

131 Y. Feng, K. Lu, L. Mao, X. Guo, S. Gao and E. J. Petersen, Water Res., 2015, 84, 49-57.

132 K. Bhattacharya, S. P. Mukherjee, A. Gallud, S. C. Burkert, S. Bistarelli, S. Bellucci, M. Bottini, A. Star and B. Fadeel, Nanomedicine: NBM, 2016, 12, 333-351.

133 M. Chen, G. Zeng, C. Lai, C. Zhang, P. Xu, M. Yan and W. Xiong, Chemosphere, 2017, 184, 127136.

134 W. Xing, G. Lalwani, I. Rusakova and B. Sitharaman, Part. Part. Syst. Char., 2014, 31, 745-750.

135 M. Chen, G. Zeng, P. Xu, Y. Zhang, D. Jiang and S. Zhou, Environ. Sci. Nano, 2017, 4, 720-727.

136 Y. Zhao, B. L. Allen and A. Star, J. Phys. Chem. A, 2011, 115, 9536-9544.

137 A. Schinwald, F. Murphy, A. Askounis, V. Koutsos, K. Sefiane, K. Donaldson and C. J. Campbell, 
Nanotoxicology, 2014, 8, 824-832.

138 D. Li, X. Hu and S. Zhang, Biomaterials, 2019, 202, 12-25.

139 S.-Y. Wu, S. S. A. An and J. Hulme, Int. J. Nanomed., 2015, 10, 9.

140 Y. Zhou, X. Jing and Y. Chen, J. Mater. Chem. B, 2017, 5, 6451-6470.

141 Q. He, D. O. Kiesewetter, Y. Qu, X. Fu, J. Fan, P. Huang, Y. Liu, G. Zhu, Y. Liu and Z. Qian, Adv. Mater., 2015, 27, 6741-6746.

142 H. Bai, W. Jiang, G. P. Kotchey, W. A. Saidi, B. J. Bythell, J. M. Jarvis, A. G. Marshall, R. A. Robinson and A. Star, J. Phys. Chem. C, 2014, 118, 10519-10529.

143 T. Li, C.-Z. Zhang and C. Gu, Environ. Technol., 2017, 38, 2999-3006.

144 L. Newman, N. Lozano, M. Zhang, S. lijima, M. Yudasaka, C. Bussy and K. Kostarelos, NPJ 2D Mater. Appl., 2017, 1, 39.

145 S. P. Mukherjee, A. R. Gliga, B. Lazzaretto, B. Brandner, M. Fielden, C. Vogt, L. Newman, A. F. Rodrigues, W. Shao and P. M. Fournier, Nanoscale, 2018, 10, 1180-1188.

146 Y. Qu, J. Wang, Q. Ma, W. Shen, X. Pei, S. You, Q. Yin and X. Li, Water Res., 2018, 143, 260-269.

147 H. Yang, X. Wu, Q. Ma, A. Yilihamu, S. Yang, Q. Zhang, S. Feng and S.-T. Yang, Chemosphere, 2019, 216, 9-18.

148 X. Hu, D. Li and L. Mu, Environ. Sci. Nano, 2017, 4, 1569-1578.

149 Y. Yan, J. Gong, J. Chen, Z. Zeng, W. Huang, K. Pu, J. Liu and P. Chen, Adv. Mater., 2019, 31, 1808283.

150 W. Chen, G. Lv, W. Hu, D. Li, S. Chen and Z. Dai, Nanotechnol. Rev., 2018, 7, 157-185.

151 C. Martín, G. Jun, R. Schurhammer, G. Reina, P. Chen, A. Bianco and C. Ménard-Moyon, Small, 2019, 15, 1905405.

152 H. Amani, E. Mostafavi, H. Arzaghi, S. Davaran, A. Akbarzadeh, O. Akhavan, H. Pazoki-Toroudi and T. J. Webster, ACS Biomater. Sci. Eng., 2018, 5, 193-214.

153 M. Loeblein, G. Perry, S. H. Tsang, W. Xiao, D. Collard, P. Coquet, Y. Sakai and E. H. T. Teo, Adv. Healthc. Mater., 2016, 5, 1177-1191.

154 C. M. Girish, A. Sasidharan, G. S. Gowd, S. Nair and M. Koyakutty, Adv. Healthc. Mater., 2013, 2, 1489-1500.

155 H. Requardt, A. Braun, P. Steinberg, S. Hampel and T. Hansen, Toxicol. in Vitro, 2019, 60, 12-18.

156 G. P. Kotchey, Y. Zhao, V. E. Kagan and A. Star, Adv. Drug Deliver. Rev., 2013, 65, 1921-1932.

157 I. Mazov, V. L. Kuznetsov, I. A. Simonova, A. I. Stadnichenko, A. V. Ishchenko, A. I. Romanenko, E. N. Tkachev and O. B. Anikeeva, Appl. Surf. Sci., 2012, 258, 6272-6280.

158 Y. Peng and H. Liu, Ind. Eng. Chem. Res., 2006, 45, 6483-6488.

159 J. C. Yang, C. H. Yen, W. J. Wang, J. J. Horng and Y. P. Tsai, J. Chem. Technol. Biot., 2010, 85, 699-707.

160 B. L. Allen, G. P. Kotchey, Y. Chen, N. V. Yanamala, J. Klein-Seetharaman, V. E. Kagan and A. Star, J. Am. Chem. Soc., 2009, 131, 17194-17205.

161 G. Modugno, F. Ksar, A. Battigelli, J. Russier, P. Lonchambon, E. E. da Silva, C. Ménard-Moyon, B. Soula, A.-M. Galibert and M. Pinault, Carbon, 2016, 100, 367-374.

162 B. L. Allen, P. D. Kichambare, P. Gou, I. I. Vlasova, A. A. Kapralov, N. Konduru, V. E. Kagan and A. Star, Nano Lett., 2008, 8, 3899-3903.

163 K. Bhattacharya, R. El-Sayed, F. T. Andón, S. P. Mukherjee, J. Gregory, H. Li, Y. Zhao, W. Seo, A. Fornara and B. Brandner, Carbon, 2015, 91, 506-517.

164 G. Chandrasekaran, S.-K. Choi, Y.-C. Lee, G.-J. Kim and H.-J. Shin, J. Ind. Eng. Chem., 2014, 20, 3367-3374.

165 C. Hu, S. Zheng, C. Lian, F. Chen, T. Lu, Q. Hu, S. Duo, R. Zhang and C. Guan, Appl. Surf. Sci., 2014, 314, 266-272.

166 J. Russier, C. Ménard-Moyon, E. Venturelli, E. Gravel, G. Marcolongo, M. Meneghetti, E. Doris and A. Bianco, Nanoscale, 2011, 3, 893-896.

167 I. Vlasova, A. Sokolov, A. Chekanov, V. Kostevich and V. Vasilyev, Russ. J. Bioorganic Chem., 2011, 37, 453.

168 V. E. Kagan, A. A. Kapralov, C. M. St. Croix, S. C. Watkins, E. R. Kisin, G. P. Kotchey, K. Balasubramanian, I. I. Vlasova, J. Yu and K. Kim, ACS Nano, 2014, 8, 5610-5621.

169 D. Elgrabli, W. Dachraoui, C. c. Ménard-Moyon, X. J. Liu, D. Bégin, S. Bégin-Colin, A. Bianco, F. Gazeau and D. Alloyeau, ACS Nano, 2015, 9, 10113-10124.

170 J. Hou, B. Wan, Y. Yang, X.-M. Ren, L.-H. Guo and J.-F. Liu, Int. J. Mol. Sci., 2016, 17, 409.

171 Y. Ding, R. Tian, Z. Yang, J. Chen and N. Lu, J. Mater. Sci. Mater. Med., 2017, $28,7$.

172 I. I. Vlasova, T. V. Vakhrusheva, A. V. Sokolov, V. A. Kostevich, A. A. Gusev, S. A. Gusev, V. I. Melnikova and A. S. Lobach, Toxicol. Appl. Pharm., 2012, 264, 131-142.

173 J. Russier, L. Oudjedi, M. Piponnier, C. Bussy, M. Prato, K. Kostarelos, B. Lounis, A. Bianco and L. Cognet, Nanoscale, 2017, 9, 4642-4645.

174 M. L. Schipper, N. Nakayama-Ratchford, C. R. Davis, N. W. S. Kam, P. Chu, Z. Liu, X. Sun, H. Dai and S. S. Gambhir, Nat. Nanotechnol., 2008, 3, 216.

175 D. Elgrabli, M. Floriani, S. Abella-Gallart, L. Meunier, C. Gamez, P. Delalain, F. Rogerieux, J. 
Boczkowski and G. Lacroix, Part. Fibre Toxicol., 2008, 5, 20.

176 R. Singh, D. Pantarotto, L. Lacerda, G. Pastorin, C. Klumpp, M. Prato, A. Bianco and K. Kostarelos, Proc. Natl. Acad. Sci. U.S.A, 2006, 103, 3357-3362.

177 Z. Liu, C. Davis, W. Cai, L. He, X. Chen and H. Dai, Proc. Natl. Acad. Sci. U.S.A, 2008, 105, 14101415.

178 A. A. Shvedova, A. A. Kapralov, W. H. Feng, E. R. Kisin, A. R. Murray, R. R. Mercer, C. M. S. Croix, M. A. Lang, S. C. Watkins and N. V. Konduru, PLoS one, 2012, 7, e30923.

179 D. Mata, M. Amaral, A. J. Fernandes, B. Colaco, A. Gama, M. C. Paiva, P. S. Gomes, R. F. Silva and M. H. Fernandes, Nanoscale, 2015, 7, 9238-9251.

180 K. Kostarelos, Nat. Rev. Mater., 2016, 1, 1-2.

181 Z. Guo, J. Ouyang, N. Y. Kim, J. Shi and X. Ji, Chemphyschem, 2019, 20, 2417-2433.

182 L. Cheng, X. Wang, F. Gong, T. Liu and Z. Liu, Adv. Mater., 2020, 32, 1902333.

183 B. Yang, Y. Chen and J. Shi, Chem, 2018, 4, 1284-1313.

184 H. Zhou, J. Ge, Q. Miao, R. Zhu, L. Wen, J. Zeng and M. Gao, Bioconjugate Chem., 2020, 31, 315331.

185 X. Ge, Z. Xia and S. Guo, Adv. Funct. Mater., 2019, 29.

186 Z. Wang, Z. Liu, C. Su, B. Yang, X. Fei, Y. Li, Y. Hou, H. Zhao, Y. Guo, Z. Zhuang, H. Zhong and Z. Guo, Curr. Med. Chem., 2019, 26, 1788-1805.

187 M. Qiu, A. Singh, D. Wang, J. Qu, M. Swihart, H. Zhang and P. N. Prasad, Nano Today, 2019, 25, 135-155.

188 A. Naskar and K. S. Kim, Microb. Pathog., 2019, 137, 103800.

189 C. Sun, L. Wen, J. Zeng, Y. Wang, Q. Sun, L. Deng, C. Zhao and Z. Li, Biomaterials, 2016, 91, 8189.

190 H. Liu, M. Sun, Y. Su, D. Deng, J. Hu and Y. Lv, Chem. Commun., 2018, 54, 7987-7990.

191 Y. Huang, J. Qiao, K. He, S. Bliznakov, E. Sutter, X. Chen, D. Luo, F. Meng, D. Su, J. Decker, W. Ji, R. S. Ruoff and P. Sutter, Chem. Mater., 2016, 28, 8330-8339.

192 S. Walia, Y. Sabri, T. Ahmed, M. R. Field, R. Ramanathan, A. Arash, S. K. Bhargava, S. Sriram, M. Bhaskaran, V. Bansal and S. Balendhran, 2D Mater., 2017, 4.

193 Z. Hu, Q. Li, B. Lei, Q. Zhou, D. Xiang, Z. Lyu, F. Hu, J. Wang, Y. Ren, R. Guo, E. Goki, L. Wang, C. Han, J. Wang and W. Chen, Angew. Chem. Int. Ed., 2017, 56, 9131-9135.

194 M. van Druenen, F. Davitt, T. Collins, C. Glynn, C. O'Dwyer, J. D. Holmes and G. Collins, Langmuir, 2019, 35, 2172-2178.

195 Q. Zhou, Q. Chen, Y. Tong and J. Wang, Angew. Chem. Int. Ed., 2016, 55, 11437-11441.

196 M. Kim, H. G. Kim, S. Park, J. S. Kim, H. J. Choi, S. Im, H. Lee, T. Kim and Y. Yi, Angew. Chem. Int. Ed., 2019, 58, 3754-3758.

197 S. Zhang, X. Zhang, L. Lei, X. F. Yu, J. Chen, C. Ma, F. Wu, Q. Zhao and B. Xing, Angew. Chem. Int. Ed., 2019, 58, 467-471.

198 Z. Li, H. Xu, J. Shao, C. Jiang, F. Zhang, J. Lin, H. Zhang, J. Li and P. Huang, Appl. Mater. Today, 2019, 15, 297-304.

199 L. Tong, Q. Liao, Y. Zhao, H. Huang, A. Gao, W. Zhang, X. Gao, W. Wei, M. Guan, P. K. Chu and H. Wang, Biomaterials, 2019, 193, 1-11.

200 J. Shao, H. Xie, H. Huang, Z. Li, Z. Sun, Y. Xu, Q. Xiao, X. F. Yu, Y. Zhao, H. Zhang, H. Wang and P. K. Chu, Nat. Commun., 2016, 7, 12967.

201 J. Plutnar, Z. Sofer and M. Pumera, ACS Nano, 2018, 12, 8390-8396.

202 G. Abellan, S. Wild, V. Lloret, N. Scheuschner, R. Gillen, U. Mundloch, J. Maultzsch, M. Varela, F. Hauke and A. Hirsch, J. Am. Chem. Soc., 2017, 139, 10432-10440.

203 W. Tao, X. Ji, X. Xu, M. A. Islam, Z. Li, S. Chen, P. E. Saw, H. Zhang, Z. Bharwani, Z. Guo, J. Shi and O. C. Farokhzad, Angew. Chem. Int. Ed., 2017, 56, 11896-11900.

204 A. A. Kistanov, S. K. Khadiullin, K. Zhou, S. V. Dmitriev and E. A. Korznikova, J. Mater. Chem. C, 2019, 7, 9195-9202.

205 M. Naguib, M. Kurtoglu, V. Presser, J. Lu, J. Niu, M. Heon, L. Hultman, Y. Gogotsi and M. W. Barsoum, Adv. Mater., 2011, 23, 4248-4253.

206 H. Huang, R. Jiang, Y. Feng, H. Ouyang, N. Zhou, X. Zhang and Y. Wei, Nanoscale, 2020, 12, 13251338.

207 H. Lin, Y. Chen and J. Shi, Adv. Sci., 2018, 5, 1800518.

208 G. Liu, J. Zou, Q. Tang, X. Yang, Y. Zhang, Q. Zhang, W. Huang, P. Chen, J. Shao and X. Dong, ACS Appl. Mater. Interfaces, 2017, 9, 40077-40086.

209 H. Lin, X. Wang, L. Yu, Y. Chen and J. Shi, Nano Lett., 2017, 17, 384-391.

210 C. Dai, H. Lin, G. Xu, Z. Liu, R. Wu and Y. Chen, Chem. Mater., 2017, 29, 8637-8652.

211 L. Zong, H. Wu, H. Lin and Y. Chen, Nano Res., 2018, 11, 4149-4168.

212 W. He, K. Ai, C. Jiang, Y. Li, X. Song and L. Lu, Biomaterials, 2017, 132, 37-47.

213 C. Dai, Y. Chen, X. Jing, L. Xiang, D. Yang, H. Lin, Z. Liu, X. Han and R. Wu, ACS Nano, 2017, 11, 12696-12712.

214 W. Feng, R. Wang, Y. Zhou, L. Ding, X. Gao, B. Zhou, P. Hu and Y. Chen, Adv. Funct. Mater., 2019, 
29.

215 C. Zhang, S. B. Wang, Z. X. Chen, J. X. Fan, Z. L. Zhong and X. Z. Zhang, Nanoscale, 2019, 11, 2027-2036.

216 H. Lin, S. Gao, C. Dai, Y. Chen and J. Shi, J. Am. Chem. Soc., 2017, 139, 16235-16247.

217 C. Tan and H. Zhang, Chem. Soc. Rev., 2015, 44, 2713-2731.

218 F. Mao, L. Wen, C. Sun, S. Zhang, G. Wang, J. Zeng, Y. Wang, J. Ma, M. Gao and Z. Li, ACS Nano, 2016, 10, 11145-11155.

219 H. Zhang, T. Wang, W. Qiu, Y. Han, Q. Sun, J. Zeng, F. Yan, H. Zheng, Z. Li and M. Gao, Nano Lett., 2018, 18, 4985-4992.

220 S. Zhang, C. Sun, J. Zeng, Q. Sun, G. Wang, Y. Wang, Y. Wu, S. Dou, M. Gao and Z. Li, Adv. Mater., 2016, 28, 8927-8936.

221 X. Chen, S. M. Shinde, K. P. Dhakal, S. W. Lee, H. Kim, Z. Lee and J.-H. Ahn, NPG Asia Mater., 2018, 10, 810-820.

222 L. Chen, Y. Feng, X. Zhou, Q. Zhang, W. Nie, W. Wang, Y. Zhang and C. He, ACS Appl. Mater. Interfaces, 2017, 9, 17347-17358.

223 J. Hao, G. Song, T. Liu, X. Yi, K. Yang, L. Cheng and Z. Liu, Adv. Sci., 2017, 4, 1600160.

224 G. Guan, X. Wang, B. Li, W. Zhang, Z. Cui, X. Lu, R. Zou and J. Hu, Nanoscale, 2018, 10, 1790217911.

225 Z. Xie, D. Wang, T. Fan, C. Xing, Z. Li, W. Tao, L. Liu, S. Bao, D. Fan and H. Zhang, J. Mater. Chem. $B, 2018,6,4747-4755$.

226 N. Ma, M.-K. Zhang, X.-S. Wang, L. Zhang, J. Feng and X.-Z. Zhang, Adv. Funct. Mater., 2018, 28, 1801139

227 C. Huang, Z. Sun, H. Cui, T. Pan, S. Geng, W. Zhou, P. K. Chu and X. F. Yu, ACS Appl. Mater. Interfaces, 2019, 11, 27521-27528.

228 L. He, T. Nie, X. Xia, T. Liu, Y. Huang, X. Wang and T. Chen, Adv. Funct. Mater., 2019, $29,1901240$. 229 H. Zhang, G. Chen, B. Yu, Y. Shen and H. Cong, ACS Appl. Bio Mater., 2019, 2, 3870-3876.

230 Y. Liu, X. Ji, J. Liu, W. W. L. Tong, D. Askhatova and J. Shi, Adv. Funct. Mater., 2017, 27, 1703261.

231 X. Qian, S. Shen, T. Liu, L. Cheng and Z. Liu, Nanoscale, 2015, 7, 6380-6387.

232 L. S. Lin, J. Song, L. Song, K. Ke, Y. Liu, Z. Zhou, Z. Shen, J. Li, Z. Yang, W. Tang, G. Niu, H. H. Yang and X. Chen, Angew. Chem. Int. Ed., 2018, 57, 4902-4906.

233 Y. Chen, D. Ye, M. Wu, H. Chen, L. Zhang, J. Shi and L. Wang, Adv. Mater., 2014, 26, 7019-7026.

234 Q. Chen, L. Feng, J. Liu, W. Zhu, Z. Dong, Y. Wu and Z. Liu, Adv. Mater., 2016, 28, 7129-7136.

235 R. Deng, X. Xie, M. Vendrell, Y. T. Chang and X. Liu, J. Am. Chem. Soc., 2011, 133, $20168-20171$.

236 J. Li, D. Li, R. Yuan and Y. Xiang, ACS Appl. Mater. Interfaces, 2017, 9, 5717-5724.

237 Y. Liu, Q. Jia, Q. Guo, W. Wei and J. Zhou, Biomaterials, 2018, 180, 104-116.

238 W. Yin, T. Bao, X. Zhang, Q. Gao, J. Yu, X. Dong, L. Yan, Z. Gu and Y. Zhao, Nanoscale, 2018, 10, 1517-1531.

239 Y. Chen, A. R. Khan, D. Yu, Y. Zhai, J. Ji, Y. Shi and G. Zhai, J. Colloid Interface Sci., 2019, 553, 567-580.

240 I. C. Taskin, O. Sen, M. Emanet, M. Culha and B. Yilmaz, Beilstein Arch., $2019,201965$. doi:10.3762/bxiv.2019.65.v1.

241 M. Xu, G. Yang, H. Bi, J. Xu, L. Feng, D. Yang, Q. Sun, S. Gai, F. He, Y. Dai, C. Zhong and P. Yang, Chem. Eng. J., 2019, 360, 866-878.

242 L. Feng, F. He, B. Liu, G. Yang, S. Gai, P. Yang, C. Li, Y. Dai, R. Lv and J. Lin, Chem. Mater., 2016, 28, 7935-7946.

243 X. Zhang, X. Xie, H. Wang, J. Zhang, B. Pan and Y. Xie, J. Am. Chem. Soc., 2013, 135, $18-21$.

244 H. Zhu, Y. Zhang, L. Zhang, T. Yu, K. Zhang, H. Jiang, L. Wu and S. Wang, J. Mater. Chem. C, 2014, 2, 7126-7132.

245 F. Zhao, Z. Li, L. Wang, C. Hu, Z. Zhang, C. Li and L. Qu, Chem. Commun., 2015, 51, 13201-13204. 246 S. Kang, Z. Fang, M. He, M. Chen, Y. Gao, D. Sun, Y. Liu, M. Chen, M. Dong, P. Liu and L. Cui, J. Colloid Interface Sci., 2020, 563, 336-346.

247 Z. Cao, L. Zhang, K. Liang, S. Cheong, C. Boyer, J. J. Gooding, Y. Chen and Z. Gu, Adv. Sci., 2018, 5, 1801155.

248 C.-Y. Ciou, S.-Y. Li and T.-M. Wu, Eur. Polym. J., 2014, 59, 136-143.

249 Y. Li, Z. Gao, F. Chen, C. You, H. Wu, K. Sun, P. An, K. Cheng, C. Sun and X. Zhu, ACS Appl. Mater. Interfaces, 2018, 10, 30930-30935.

250 Z. Gao, Y. Li, Y. Zhang, K. Cheng, P. An, F. Chen, J. Chen, C. You, Q. Zhu and B. Sun, ACS Appl. Mater. Interfaces, 2019, 12, 1963-1972.

251 A. M. Evans, L. R. Parent, N. C. Flanders, R. P. Bisbey, E. Vitaku, M. S. Kirschner, R. D. Schaller, L. X. Chen, N. C. Gianneschi and W. R. Dichtel, Science, 2018, 361, 52-57.

252 S. Mura, J. Nicolas and P. Couvreur, Nat. Mater., 2013, 12, 991-1003.

253 S. Gan, X. Tong, Y. Zhang, J. Wu, Y. Hu and A. Yuan, Adv. Funct. Mater., 2019, 29, 1902757.

254 K. Wang, Z. Zhang, L. Lin, K. Hao, J. Chen, H. Tian and X. Chen, ACS Appl. Mater. Interfaces, 2019, 11, 39503-39512. 
255 S. lijima, Nature, 1991, 354, 56-58.

256 A. R. Sureshbabu, R. Kurapati, J. Russier, C. Ménard-Moyon, I. Bartolini, M. Meneghetti, K. Kostarelos and A. Bianco, Biomaterials, 2015, 72, 20-28.

257 Y. Li, L. Feng, X. Shi, X. Wang, Y. Yang, K. Yang, T. Liu, G. Yang and Z. Liu, Small, 2014, 10, 15441554.

258 A. M. Arnold, B. D. Holt, C. Tang and S. A. Sydlik, Carbon, 2019, 154, 342-349.

259 Z. Wang, A. von dem Bussche, Y. Qiu, T. M. Valentin, K. Gion, A. B. Kane and R. H. Hurt, Environ. Sci. Technol., 2016, 50, 7208-7217.

260 C. R. Ryder, J. D. Wood, S. A. Wells, Y. Yang, D. Jariwala, T. J. Marks, G. C. Schatz and M. C. Hersam, Nat. Chem., 2016, 8, 597-602.

261 H. Huang, L. He, W. Zhou, G. Qu, J. Wang, N. Yang, J. Gao, T. Chen, P. K. Chu and X.-F. Yu, Biomaterials, 2018, 171, 12-22.

262 J. D. Wood, S. A. Wells, D. Jariwala, K.-S. Chen, E. Cho, V. K. Sangwan, X. Liu, L. J. Lauhon, T. J. Marks and M. C. Hersam, Nano Lett., 2014, 14, 6964-6970.

263 A. J. Mannix, B. Kiraly, M. C. Hersam and N. P. Guisinger, Nat. Rev. Chem., 2017, 1, 1-14.

264 Q.-Q. Yang, R.-T. Liu, C. Huang, Y.-F. Huang, L.-F. Gao, B. Sun, Z.-P. Huang, L. Zhang, C.-X. Hu and Z.-Q. Zhang, Nanoscale, 2018, 10, 21106-21115.

265 A. J. Mannix, Z. Zhang, N. P. Guisinger, B. I. Yakobson and M. C. Hersam, Nat. Nanotechnol., 2018, 13, 444-450.

266 M. R. Tchalala, M. A. Ali, H. Enriquez, A. Kara, A. Lachgar, S. Yagoubi, E. Foy, E. Vega, A. Bendounan and M. G. Silly, J. Phys. Condens. Matter, 2013, 25, 442001.

267 Q. Wang, M. Safdar, K. Xu, M. Mirza, Z. Wang and J. He, ACS Nano, 2014, 8, 7497-7505.

268 T. Habib, X. Zhao, S. A. Shah, Y. Chen, W. Sun, H. An, J. L. Lutkenhaus, M. Radovic and M. J. Green, NPJ 2D Mater. Appl., 2019, 3, 1-6.

269 X. Li, Z. Huang and C. Zhi, Front. Mater., 2019, 6, 312.

270 J. Tucek, P. Blonski, J. Ugolotti, A. K. Swain, T. Enoki and R. Zboril, Chem. Soc. Rev., 2018, 47, 3899-3990.

271 W. Zhang, Z. Guo, D. Huang, Z. Liu, X. Guo and H. Zhong, Biomaterials, 2011, 32, 8555-8561.

272 S. Zhang, C. Sun, J. Zeng, Q. Sun, G. Wang, Y. Wang, Y. Wu, S. Dou, M. Gao and Z. Li, Adv. Mater., 2016, 28, 8927-8936.

273 Y. Wang, M. Qiu, M. Won, E. Jung, T. Fan, N. Xie, S.-G. Chi, H. Zhang and J. S. Kim, Coordin. Chem. Rev., 2019, 400, 213041.

274 S. Liu, X. Pan and H. Liu, Angew. Chem. Int. Ed. 2020, 59, 5890-5900.

275 M. Qiu, D. Wang, W. Liang, L. Liu, Y. Zhang, X. Chen, D. K. Sang, C. Xing, Z. Li, B. Dong, F. Xing, D. Fan, S. Bao, H. Zhang and Y. Cao, Proc. Natl. Acad. Sci. U.S.A, 2018, 115, 501-506.

276 W. Chen, J. Ouyang, H. Liu, M. Chen, K. Zeng, J. Sheng, Z. Liu, Y. Han, L. Wang, J. Li, L. Deng, Y. N. Liu and S. Guo, Adv. Mater., 2017, 29, 1603864.

277 X. Zeng, M. Luo, G. Liu, X. Wang, W. Tao, Y. Lin, X. Ji, L. Nie and L. Mei, Adv. Sci., 2018, 5, 1800510.

278 H. Wang, L. Zhong, Y. Liu, X. Xu, C. Xing, M. Wang, S. M. Bai, C. H. Lu and H. H. Yang, Chem. Commun., 2018, 54, 3142-3145.

279 O. Akhavan, J. Mater. Chem. B, 2016, 4, 3169-3190.

280 G. Lalwani, A. M. Henslee, B. Farshid, L. Lin, F. K. Kasper, Y. X. Qin, A. G. Mikos and B. Sitharaman, Biomacromolecules, 2013, 14, 900-909.

281 J. Lu, Y. S. He, C. Cheng, Y. Wang, L. Qiu, D. Li and D. Zou, Adv. Funct. Mater., 2013, 23, 34943502.

282 W. Zhang, Q. Chang, L. Xu, G. Li, G. Yang, X. Ding, X. Wang, D. Cui and X. Jiang, Adv. Healthc. Mater., 2016, 5, 1299-1309.

283 B. Yang, J. Yin, Y. Chen, S. Pan, H. Yao, Y. Gao and J. Shi, Adv. Mater., 2018, 30, 1705611.

284 H. Xie, J. Shao, Y. Ma, J. Wang, H. Huang, N. Yang, H. Wang, C. Ruan, Y. Luo, Q. Q. Wang, P. K. Chu and X. F. Yu, Biomaterials, 2018, 164, 11-21.

285 Z. Wei, D. Wang, S. Kim, S.-Y. Kim, Y. Hu, M. K. Yakes, A. R. Laracuente, Z. Dai, S. R. Marder and C. Berger, Science, 2010, 328, 1373-1376.

286 M. S. Mannoor, H. Tao, J. D. Clayton, A. Sengupta, D. L. Kaplan, R. R. Naik, N. Verma, F. G. Omenetto and M. C. McAlpine, Nat. Commun., 2012, 3, 763.

287 Y. P. Venkata Subbaiah, K. J. Saji and A. Tiwari, Adv. Funct. Mater., 2016, 26, 2046-2069.

288 Q. H. Wang, K. Kalantar-Zadeh, A. Kis, J. N. Coleman and M. S. Strano, Nat. Nanotechnol., 2012, 7, 699-712.

289 G.-H. Lee, Y.-J. Yu, X. Cui, N. Petrone, C.-H. Lee, M. S. Choi, D.-Y. Lee, C. Lee, W. J. Yoo and K. Watanabe, ACS Nano, 2013, 7, 7931-7936.

290 X. Chen, Y. J. Park, M. Kang, S. K. Kang, J. Koo, S. M. Shinde, J. Shin, S. Jeon, G. Park, Y. Yan, M. R. MacEwan, W. Z. Ray, K. M. Lee, J. A. Rogers and J. H. Ahn, Nat. Commun., 2018, 9, 1690.

291 A. Masyutin, M. Erokhina, K. Sychevskaya, A. Gusev, I. Vasyukova, E. Smirnova and G. Onishchenko, IOP Conference Series: Materials Science and Engineering, IOP Publishing, 2015, 98, 
012008.

292 K. Bhattacharya, C. Sacchetti, P. M. Costa, J. Sommertune, B. D. Brandner, A. Magrini, N. Rosato, N. Bottini, M. Bottini and B. Fadeel, Adv. Healthc. Mater., 2018, 7, 1700916.

293 D. Bitounis, H. Ali - Boucetta, B. H. Hong, D. H. Min and K. Kostarelos, Adv. Mater., 2013, 25, 22582268.

294 D. Bitounis, D. Parviz, X. Cao, C. A. Amadei, C. D. Vecitis, E. M. Sunderland, B. D. Thrall, M. Fang, M. S. Strano and P. Demokritou, Small, 2020, 1907640.

295 S. Kuriakose, T. Ahmed, S. Balendhran, V. Bansal, S. Sriram, M. Bhaskaran and S. Walia, 2D Mater., 2018, 5, 032001

296 W. Lei, G. Liu, J. Zhang and M. Liu, Chem. Soc. Rev., 2017, 46, 3492-3509.

297 N. Kong, X. Ji, J. Wang, X. Sun, G. Chen, T. Fan, W. Liang, H. Zhang, A. Xie and O. C. Farokhzad, Nano Lett., 2020, 20, 3943-3955.

298 Z. Sofer, J. Luxa, D. Bouša, D. Sedmidubský, P. Lazar, T. Hartman, H. Hardtdegen and M. Pumera, Angew. Chem. Int. Ed., 2017, 56, 9891-9896. 


\section{Graphical Abstract}

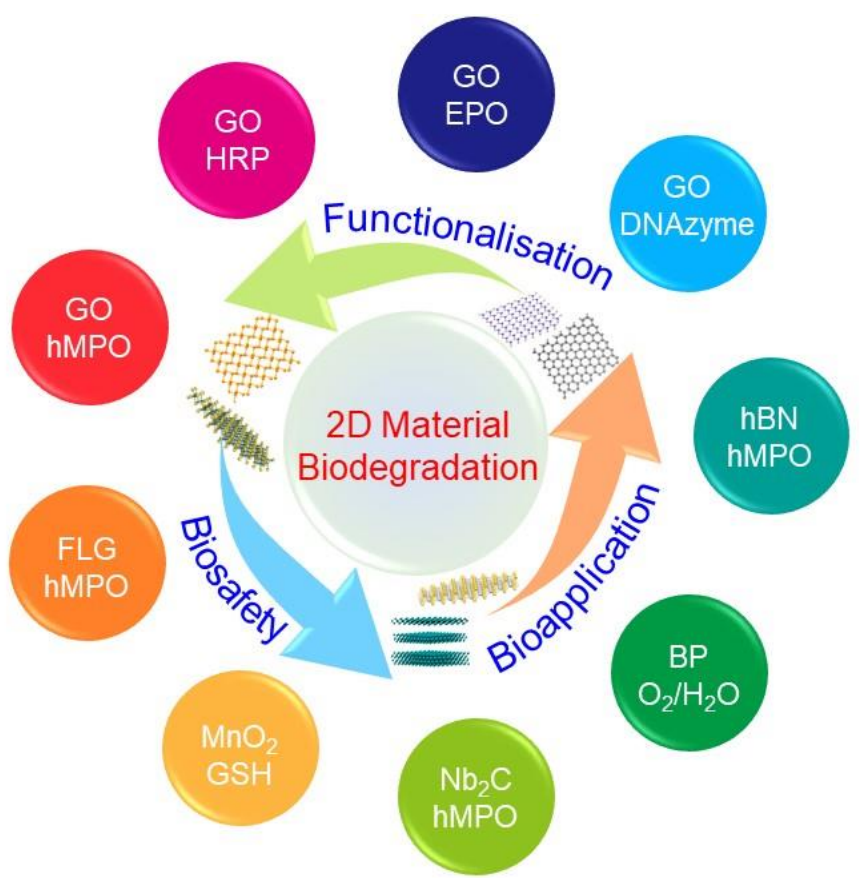




\section{Biographies}

\section{Alberto Bianco}

Dr. Alberto Bianco received his $\mathrm{PhD}$ in 1996 from the University of Padova. As a visiting scientist, he worked at the University of Lausanne, the University of Tübingen (as an Alexander von Humboldt fellow), the University of Padova and Kyoto University. He is currently Research Director at the CNRS in Strasbourg. His research interests focus on the design of multifunctional carbon-based nanomaterials for therapy, diagnostics and imaging. In 2017 he has been elected Fellow of the European Academy of Science and in 2019 he has obtained the CNRS Silver Medal. Since 2011 he is Editor of the journal CARBON.

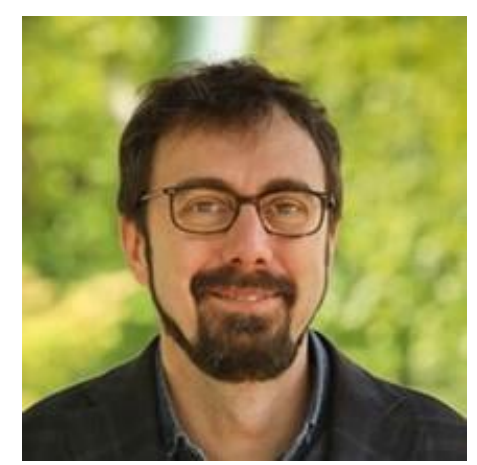

\section{Baojin Ma}

Baojin Ma received his $\mathrm{PhD}$ in 2019 from Shandong University. He is currently a postdoctoral researcher in the group of Dr. A. Bianco in the Institute of Cellular and Molecular Biology at the CNRS (Strasbourg). His research interests focus on the biodegradation of carbon nanomaterials and the preparation of graphene composite nanomaterials for cancer therapy.

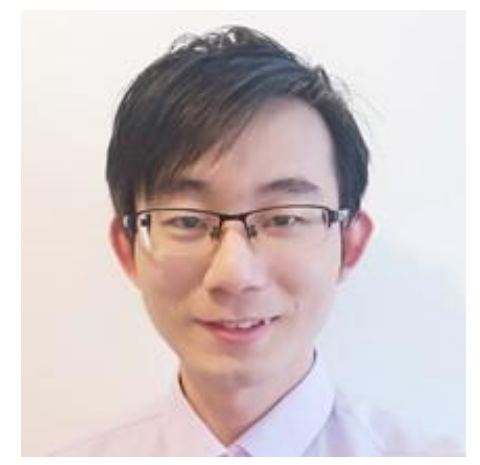

\section{Cristina Martín}

Cristina Martín finished her Chemistry studies in 2012 in the University of Castilla-La Mancha (Spain) and obtained her PhD in Chemistry in 2016 from the Universities of Trieste (Italy) and Castilla-La Mancha, working under the co-supervision of Prof. Maurizio Prato and Prof. Ester Vázquez. During her PhD, she spent 3 months at the University of Brighton (UK) under the supervision of Prof. Matteo Santin. As a postdoctoral researcher she worked in 2016-2017 at IRICA (Spain). In October 2017 she joined the group of Dr. Alberto Bianco group as postdoc. 
Her main focuses are carbon nanostructures, their biodegradation and biomedical applications.

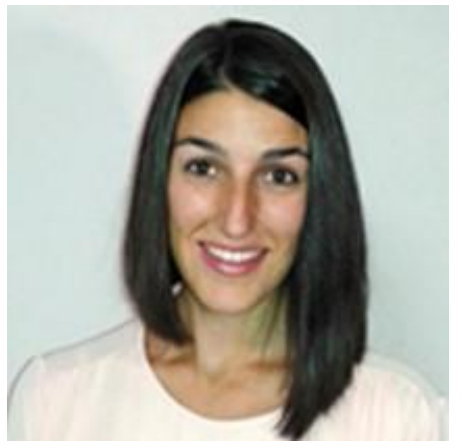

\section{Rajendra Kurapati}

Rajendra Kurapati finished his Master of Science in Chemistry at the University of Hyderabad in 2008 and obtained his $\mathrm{PhD}$ in Materials Engineering in 2014 from the Indian Institute of Science, Bangalore under supervision of Prof. A.M. Raichur. During 2014-2017, he worked as a postdoctoral fellow in Dr. A. Bianco's group at the CNRS in Strasbourg (France). In 2018, he worked as a Research Engineer with Prof. P. Marcus at Chimie ParisTech, Paris. In September 2018, Rajendra became a Marie Skłodowska-Curie fellow at CÚRAM, NUI Galway in Prof. A. Pandit's group. His main research interests are the biodegradability and the biomedical applications of $2 \mathrm{D}$ materials.

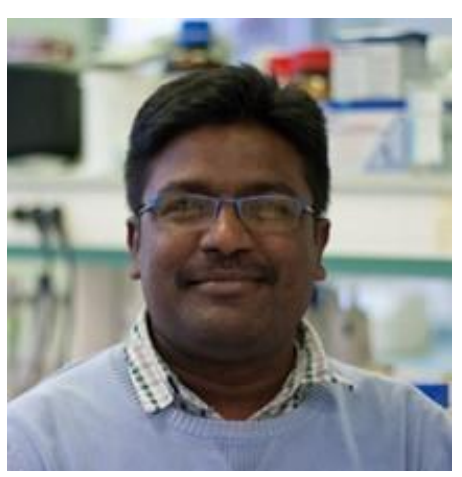

